\title{
Distributional preferences in larger groups: Keeping up with the Joneses and keeping track of the tails
}

\author{
Raymond Fisman, Ilyana Kuziemko and Silvia Vannutelli*
}

February 21, 2018

\begin{abstract}
We study distributional preferences in "large" groups. While most prior experiments have focused on exploring attitudes toward inequality in two- or three-person groups, we field a series of experiments via Mechanical Turk in which subjects choose between two income distributions, each with seven (or nine) individuals, with hypothetical incomes that aim to approximate the actual distribution of income in the U.S. Our setting thus provides a more direct comparison to the redistributive choices faced by society. Consistent with standard maximin (Rawlsian) preferences, subjects select distributions in which the bottom individual's income is higher (but show little regard for lower incomes above the bottom ranking). In contrast to standard models, however, we find that subjects select distributions that lower the top individual's income, but not other high incomes. Finally, we provide tentative evidence of "locally competitive" preferences - in most experimental sessions, subjects select distributions that lower the income of the individual directly above them, while the income of the individual two positions above has little effect on subjects' decisions. Our findings suggest that theories of inequality aversion should be enriched to account for individuals' aversion to "topmost" and "local" disadvantageous inequality.
\end{abstract}

JEL Classification Numbers: C91, D63, H23.

Key words: Inequality aversion; Envy; Redistribution

${ }^{*}$ For helpful feedback we thank John Cisternino, David Moss, Michael Norton, and seminar participants at Yale. Financial support from the Tobin Project is gratefully acknowledged. Fisman: Boston University and NBER (email: rfisman@bu.edu); Kuziemko: Princeton University and NBER (email: kuziemko@princeton.edu); Vannutelli: Boston University (email: svann@bu.edu) 


\section{Introduction}

Economists have long recognized that individuals incorporate others' payoffs into their own utility. This insight has given rise to a rich theoretical and experimental literature to better understand the structure of individuals' distributional preferences. Economists' interest in the topic is not merely academic - models of distributional preferences can help inform our understanding of support for redistributive policies, political preferences, and the provision of public goods. Much of the emphasis has been on testing various models of inequality aversion. Many of these models assume functional forms in which the incomes of others matter only in aggregate (as in, for example, Bolton and Ockenfels (2000)), or which add the possibility that individuals try to help the worst-off person (as in Rawlsian preferences, explored in Charness and Rabin (2002) and Engelmann and Strobel (2004)). Fehr and Schmidt (1999) allow the disutility created by income gaps to depend on whether the gaps are disadvanta-

geous (resulting from incomes above the individual) or advantageous (resulting from incomes below the individual), but within these two groupings income differences are just aggregated to total disadvantageous and advantageous inequality.

These models have performed well in experimental tests in which the decision-maker divides earnings between herself and a single recipient or pair of recipients. But relatively little work has explored their predictions in larger groups that may have more direct analogs in the real world. To this end, we devise a simple experiment that allows subjects to express, via revealed preference, their concern for inequality at different points in the income distribution relative to their own. As a result, we may distinguish the extent to which subjects place equal weight on the income gaps between themselves and all other individuals above them (as in the most literal interpretation of Fehr and Schmidt (1999)) or if the incomes of people in certain positions (e.g., the very top) in the income distribution appear to place higher weight on their own utility. Similarly, we can test whether all advantageous income gaps between oneself and those below carry equal weight.

Specifically, we conduct a set of experiments via Mechanical Turk (MTurk) in which each subject is confronted with a choice between two hypothetical societies $A$ and $B$, each with a different income distribution. In most versions of the experiment, each distribution is comprised of seven individuals, including the subject herself. The two societies have different income distributions, generated by taking independent draws from the same underlying process. The data generating processes are designed to be reflective of the rough level of prosperity in the United States, but to have some tilt toward the upper right tail, given distributional preferences over this group will have the largest tax implications as a result of their disproportionate share of income. For example, a typical distribution would be $\{\$ 10,934$, 
$\$ 28,102, \$ 62,275, \$ 92,479, \$ 107,973, \$ 151,869, \$ 188,371\})$. By construction, in most variants, the subject's own income is held constant in Societies $A$ and $B$ (e.g., if she were the fourthranked person in the given example, her income would be $\$ 92,479$ and have a rank of four in both distributions, whereas the other values would vary, independently sampled from the given generating process). We make this choice to emphasize the role of others' payoffs in choosing distributional outcomes. Our design allows us to distinguish, for example, whether individuals put more weight on reducing inequality at extreme income levels, or focus on inequality nearer to the subject's own income.

Our first set of results does not explicitly consider the position of the subject herself, but focuses instead on whether certain positions - most obviously the highest- and lowest-ranked ones - play a particularly prominent role in subjects' choices. We find a very robust emphasis on reducing extreme inequality. Consistent with Rawlsian preferences and the results in Charness and Rabin (2002) for two- and three-subject settings, subjects are significantly more likely to select the distribution that raises the bottom individual's income. This effect is very large: a subject is about 30 percentage points more likely to select the distribution in which the least well-off individual's income is higher. More novel, we also find a robust and quantitatively important emphasis on lowering the income of the individual in the highest position in the distribution - subjects are more than ten percentage points more likely to select the distribution with a lower income in the top position, all else equal. Apart from the top and bottom incomes, no other absolute position has any impact on subjects' decisions.

In our second set of results, we define others' positions in a relative sense: one position above the subject, one below the subject, and so forth. We observe a large and significant desire to reduce the income of the individual in the position directly above the subject's own income. In fact, this effect is comparable in magnitude to subjects' preference for lowering the income of the individual at the highest position in the distribution. By contrast, the income two positions above her has no impact on the choice of distribution, and we can reject at high levels of precision that these two effects are of equal magnitude. Such a result is inconsistent with a general desire to reduce inequality.

To organize our findings, we introduce the distinction between locally competitive versus topmost competitive preferences to reflect our subjects' particular focus on incomes very close to their own as well as those at the top tail of the distribution. This framing can provide some (parsimonious) guidance on the weights that individuals place on inequalities at particular ranks in the income distribution, thereby enriching models of inequality aversion that are standard in the literature. In particular, we can reject that individuals treat disadvantageous income gaps symmetrically: instead we show that the immediate income gap between the subject and the person right above her as well as the income gap between her and the richest 
person matter more than all other disadvantageous gaps. Similarly, we can reject that all advantageous inequality is equal: instead, the advantageous inequality between the subject and the worst-off person appears to differentially reduce utility.

Our framework may also help to reconcile some attitudes toward inequality that are harder to explain with standard models. For example, consideration of local versus topmost competitiveness is consistent with the popular outrage over the high incomes of the top one percent. It can similarly explain why people care about "keeping up with the Jones" while at the same time ignoring the somewhat more prosperous Johnsons. ${ }^{1}$

In the year following our initial pair of experiments (conducted in September, 2013), we ran a number of additional "sessions" (given we use MTurk and not a true lab, "sessions" is a slight abuse of the language, but by "session" we mean separate MTurk surveys administered at particulars dates and times) that subjected our analysis to a wide range of robustness checks. We allowed the subject's own income to differ across the two distributions, varied the generating processes to create distributions with higher levels of inequality, and increased the number of individuals in each "society" to nine. We also varied the way that the distributions were presented to subjects, pulling the bar representing the subject's own income away from those representing the incomes of others. Up to this point, all experiments confronted subjects with hypothetical choices between pairs of income distributions. In our final variant, we ran a real-stakes version in which subjects were informed that, with ten percent probability, their choice would be implemented for stakes equal to one ten-thousandth of the income distributions presented, with randomly drawn MTurk workers as recipients. Thus, for example, if an individual in a selected distribution was assigned an income of $\$ 140,000$ and that distribution was selected for real payoffs, a random MTurk worker would receive $\$ 14$ as payment.

We find that subjects in every session tended to choose distributions that reduce the income of the individual in the highest position (i.e., subjects always exhibit topmost competitiveness) and increase the income of the individual in the lowest position. Evidence for "locally competitive" preferences is also observed in every variant apart from the "real stakes" session, where its measured effect is much weaker (and statistically insignificant). We return to discuss some possible explanations for this pattern when we present our experimental findings.

Our paper contributes most directly to the recent literature that aims to infer redistribu-

\footnotetext{
${ }^{1}$ For example, Luttmer (2005) shows that within relatively small geographic units, average local income negatively predicts individual well-being, holding one's own income constant. As these units are more economically homogeneous than the entire country, the result suggests that individuals care about the incomes of those close to them in the distribution (though that interpretation is confounded by geographic proximity).
} 
tive preferences via survey methods. These studies have generally been devised to better understand attitudes toward (and impediments to) inequality-reducing redistribution in general (e.g., Kuziemko et al. (2015), Norton and Ariely (2011)), without exploring the particular structure of these preferences.

More broadly, our work builds on the large body of research that aims to characterize the nature of distributional preferences. In our experimental design, we attempt to bridge social preferences as typically studied in small groups with small stakes to preferences over more policy-relevant income distributions. The literature we build upon encompasses the theoretical contributions referenced earlier, many of which have experimental components to them involving just one or two recipients. ${ }^{2}$

Our paper joins a smaller literature on distributional preference experiments involving large groups. These studies tend to impose a formulaic redistribution parameter such that all poorer individuals are made better off and all richer individuals made worse off, potentially subject to some efficiency loss (see, in particular, Durante et al. (2014), Ackert et al. (2007), and Beckman et al. (2004)). While this has the advantage of mimicking the effects of taxation, it does not allow these prior studies to separate subjects' concerns for others' incomes at particular points in the distribution. ${ }^{3}$

As our subjects are in a sense acting as social planners (though they are "planning" a society of which they are a member), our work relates to the optimal tax literature under non-standard preferences (either of the social planner herself or of individuals in society). Recently, several important contributions on the theory side of this question have emerged. Saez and Stantcheva (2016) examines optimal tax outcomes when the social planner is lossaverse, Farhi and Gabaix (2015) develops optimal tax formulae under a number of behavioral anomalies (e.g., inattention and mental accounting), and Lockwood (2016) focuses on present bias. Our approach, as in Charité et al. (2015a), who test whether social planners respect

\footnotetext{
${ }^{2}$ See Kahneman et al. (1986) for the earliest dictator experiment and Forsythe et al. (1994) for the first appearance of the standard dictator game. More recent research has explored how dictators' fairness principles are affected by considerations such as deservingness (e.g., Almas et al. (2010), Krawczyk (2010)) and extrinsic versus intrinsic motivations (Cappelen et al. (2017)). Recent research has also generalized the dictator framework to incorporate different prices of giving to create a tradeoff between equality and efficiency (see Andreoni and Miller (2002) and Fisman et al. (2007)). We see our work as extending this tradition to consider the more complex set of tradeoffs that come with distributional choices involving multiple others.

${ }^{3}$ While less directly related to distributive preferences, a recent paper examines decision-making in groups far larger than those in typical experiments. Schumacher et al. (forthcoming) finds that many subjects make welfare-decreasing decisions while acting as social planners for large (up to 32 individuals) groups in lab experiments, because subjects weigh a salient benefit for a minority of the group as more important than a small cost for the majority of the group, even if the sum of the costs is greater than the sum of the benefits.
} 
individuals' reference points, is more experimental. ${ }^{4}$

The remainder of the paper is organized as follows. Section 2 develops a very simple generalization of the Fehr-Schmidt model that we will use to guide our empirical analysis. Section 3 describes the experimental design. Section 4 explains the data collection procedure. Section 5 presents the results from our main experiment as well as the follow-up sessions. Section 6 offers concluding thoughts and suggestions for future work.

\section{Standard models of distributional preferences}

In this section, we summarize the classic inequality aversion model of Fehr and Schmidt (1999), and also present a more flexible (though less parsimonious) version that will serve as a point of departure for our empirical exercise.

We begin with the Fehr-Schmidt model. Consider a society of $n$ individuals and a vector of payoffs $\mathbf{x}=\left(x_{1}, \ldots, x_{n}\right)$; the utility function of individual $i$ is then given by:

$$
U_{i}(\mathbf{x})=x_{i}-\frac{\alpha_{i}}{n-1} \sum \max \left\{x_{j}-x_{i}, 0\right\}-\frac{\beta_{i}}{n-1} \sum \max \left\{x_{i}-x_{j}, 0\right\}
$$

where $\alpha_{i}$ is individual $i$ 's aversion to disadvantageous inequality and $\beta_{i}$ is his aversion to advantageous inequality. The model assumes $0 \leq \beta_{i}<1$ and $\alpha_{i} \geq \beta_{i}$. These conditions imply that individuals do not like advantageous or disadvantageous inequality $\left(\alpha_{i}, \beta_{i} \geq 0\right)$, but that they are not willing to reduce own-income in order to reduce inequality $\left(\beta_{i}<1\right)$, holding others' incomes constant. The second assumption implies additionally that players dislike falling behind more than they dislike being ahead of others.

In our setting, in which own-income is held constant (though we relax this constraint in one experimental session), this model predicts that subjects will choose the distribution that minimizes the aggregate payoff differences relative to others, with a greater weight on

\footnotetext{
${ }^{4}$ In comparing our results from hypothetical and real-stakes settings, we also contribute to a small literature that seeks to test whether non-incentivized results generalize to incentivized settings. In general, earlier research on this topic has found mixed results. Camerer and Hogarth (1999) perform a meta-analysis of 74 studies that either have no, low or high-powered incentives. They find that the effect of real stakes depends on the experimental task. Beattie and Loomes (1997) compare three payment schemes: hypothetical, randomly picking one of several questions for payment, and paying out for each question. They find that choices involving pair-wise comparisons of lotteries are not affected by payment (although subjects are less likely to violate expected utility theory over complicated sequences of lotteries when they are paid for each question). By contrast, while our pair-wise comparisons are not tests of rationality, we do find that payment matters for subjects' decisions. Etchart-Vincent and l'Haridon (2011) find that hypothetical and incentivized choices do not differ for the choice to bear risk in the loss domain, but that hypothetical choices in the gain domain are more risk-seeking than incentivized choices (consistent with Holt and Laury (2002)).
} 
decreasing high incomes rather than increasing low incomes. However, the model makes no distinction among all individuals above the subject's income or all individuals below: all incomes within each group are given the same weight, $\frac{\alpha_{i}}{n-1}$ or $\frac{\beta_{i}}{n-1}$, respectively. ${ }^{5}$

Individual- or rank-specific specific comparisons can easily be embedded in the FehrSchmidt model by allowing parameters to vary for each of the other individuals' positions. Without loss of generality, we order the vector of incomes $\mathbf{x}$ in increasing order, so that the fully flexible Fehr-Schmidt model may be expressed as:

$$
U_{i}(\mathbf{x})=x_{i}-\frac{1}{n-1} \sum_{j=i+1}^{n} \alpha_{i, j}\left(x_{j}-x_{i}\right)-\frac{1}{n-1} \sum_{j=1}^{i-1} \beta_{i, j}\left(x_{i}-x_{j}\right)
$$

Our experimental design allows us to potentially estimate all of these individuals' specific weights $\left(\alpha_{i, j}\right.$ and $\left.\beta_{i, j}\right)$. If we allowed for a fully flexible specification, it would lead to a very large number of parameters (since they potentially depend on where the subject is in the income distribution). As a result, we will present a set of graphs at the beginning of Section 5 that displays each of these parameters. We then inspect the patterns to determine the regression specifications that the data appear to suggest. While there is some subjectivity in going from the patterns in the graphs to an explicit regression specification, we will be aided in this endeavor by the fact that we observe very clear patterns in the data: subjects' inequality aversion focuses on the top and bottom individuals' incomes (captured by $\alpha_{i, n}$ and $\beta_{i, 1}$ respectively), and locally disadvantageous inequality aversion (captured by $\alpha_{i, i+1}$ ).

\section{Experimental Design}

The centerpiece of the survey presents each subject with a binary choice between two income distributions, which are called "Society A" and "Society B." The survey experiment begins with the following initial instructions (or a close variant of them, depending on whether we were running the main survey experiment or one of the modified versions that we ran to explore the robustness of our various findings):

In each round you will see two graphs displayed on your screen. Each graph represents a distribution of payoffs that you can choose to assign to yourself and to the other participants in your group. In each round, you must decide which distribution, Society $A$ or Society $B$, you prefer.

\footnotetext{
${ }^{5}$ Bolton and Ockenfels (2000) adopt an approach that similarly yields no prediction of either locally or topmost competitive preferences, based on the utility function $U_{i}(x)=U\left(x_{i}, \frac{x_{i}}{\sum x_{j}}\right)$
} 
Subjects then completed a practice round, which was accompanied by the following instructions:

Two graphs are displayed below. Each graph represents a distribution of payoffs that you can choose to assign to yourself and the other participants in your group. The red bar in each graph indicates your position and payoff in the group. Please select which distribution you prefer.

After completing the practice round, subjects confirmed that they had read and understood the directions before completing the ten subsequent iterations that constitute the data we use in our analysis (see the screenshot in Figure 1). ${ }^{6}$

In every iteration, the subject's own position in the income distribution was selected at random. Further, in each iteration, instructions were reprinted above the two graphs, as shown in the screenshot. Following the last iteration, subjects completed a short survey on their attitudes toward government redistribution, their political preferences and voting decisions, and basic demographics like age, gender, and income.

We focus our presentation of the results from the initial pair of experimental sessions that we conducted, on September $9^{\text {th }}$ and September $17^{\text {th }}, 2013$. In both sessions, subjects were presented with choices that took the precise form illustrated in Figure 1, differing only in the process by which the income distribution values were generated.

The income values for these sessions were drawn from uniform distributions in each of seven ranges: $\left(a_{1}, b_{1}\right),\left(a_{2}, b_{2}\right) \ldots\left(a_{7}, b_{7}\right)$, where the subscripts denote the position $p \in$ $\{1,2, \ldots, 7\}$ in the distribution. Note that position, as we define it, is increasing in income, as opposed to rank. We set $b_{p}=a_{p+1}$, so that the union of the intervals is $\left(a_{1}, b_{7}\right) \backslash\left\{b_{1}, b_{2}, \ldots, b_{6}\right\}$ (i.e., the full interval minus a subset of measure zero). The non-overlapping ranges ensure that in no case can ranks change from Society $A$ to Society $B$. As such, if the subject finds herself in position 4 in Society $A$, she will be in position 4 in Society $B$. We made this choice to simplify the setting: the person right above a subject may move closer or further away, but the subject can never "leapfrog" over him (nor can the subject be leapfrogged by the person directly below).

To probe robustness, in our main experimental sessions we vary how the $a_{p}$ and $b_{p}$ values are set. In one case, which we term "Absolute Differences" (AD), the ranges were kept constant, in $\$ 20,000$ increments, beginning at $\$ 10,000$ (i.e., 10,000-30,000, 30,000$50,000 \ldots 130,000-150,000)$. To give some sense of where these values sit in the distribution of U.S. pre-tax, pre-transfer income, the midpoint of the lowest interval is at roughly the

\footnotetext{
${ }^{6}$ Subjects were additionally assured that all responses would remain anonymous.
} 
24th percentile and the midpoint of the highest interval is at roughly the 94 th. $^{7}$ In the second case, which we term "Percentage Differences" (PD), we keep the percentage increase in a comparable range across positions in the income distribution, increasing the range by $\$ 5,000$ at each level (i.e., the ranges are 10,000-25,000, 25,000-45,000 . 175,000-220,000). As indicated in the instructions, the subject's own income is presented in a different color in both distributions, and in all cases the subject's own income is identical in each distribution to focus the decision-maker on inequality rather than own-income.

We conducted a number of variants on this basic design to probe the robustness of our results to different income distributions and ways of presenting them to subjects. These variants allow own income to vary; provide an alternative presentation of the income distributions, to ensure that the results are not driven by the particular manner in which income distributions are presented; change the distribution from which the income values are drawn; and make the experiment for "real money." We describe these companion experiments in greater detail after documenting the results of the main experiment.

Table A1 provides a full list of the treatments (the main experiments plus the companion experiments) as well as the dates they were conducted.

The interested reader can take the full experiment online at nautech-clients.com/ tobin/survey12/. The version posted online is the "real stakes" session (described in detail in Section 5.3; its instructions are virtually identical to those of the main experiment, with the addition of a screen which explains how payoffs will be determined as a result of the subject's choices in the experiment).

\section{Data Collection}

Over the past few years, social scientists have increasingly used MTurk to perform experiments and collect survey data (see Kuziemko et al., 2015 and papers cited therein for a review). We registered as a requester and created a human intelligence task (HIT) titled "5-10 Minute Survey About Income Preferences". 8 To limit selection bias while also giving workers an honest description of the task, we provided a short, neutral description of the HIT ("This survey is part of an academic research survey") that could be viewed by workers

\footnotetext{
${ }^{7}$ These percentiles are based on the 2016 CPS. The midpoint of the second interval is at roughly the 52nd, that of the third at the 72nd, that of the fourth at the $82 \mathrm{nd}$, that of the fifth at the 88th, and that of the sixth at the 92nd. As noted in the introduction, we wanted distributions with some skew to the right.

${ }^{8}$ Two sessions of the survey were administered with small changes to the HIT title. One session was run with the title "7-10 Minute Survey About Income Preferences", and another was run with the title "10 Minute Research Survey About Income Preferences".
} 
before they signed up to participate. Compensation was set to $\$ .50$ which, given the median completion time of seven minutes, works out to an hourly wage of $\$ 4.25$. Though we cannot find official data on average wages on MTurk, reading through worker forums suggests that we are paying a generous wage (and indeed our posted surveys were always filled within a short period of time).

Each worker logs in with an MTurk worker ID. We collected data over seven separate sessions, dropping any worker who had taken a previous survey with the same ID so as to gather a fresh sample each time (though our main results hold when we keep repeat-takers in the sample, as we show later). The sessions differed in the way that the income distributions were generated or presented, as detailed in the preceding section.

To limit heterogeneity of the sample, we collected all data on workdays during daylight hours on the East Coast of the United States. Individuals were prompted for a response if they tried to skip questions (to further discourage robots and inattentive respondents). We also limited the survey's availability to those with U.S. billing addresses and asked respondents to confirm their residency in the United States. We further limit respondents to those with positive ratings from at least 90 percent of past MTurk requesters. Basic cross-tabs of the data are reassuring (for example, subjects who report Republican party affiliation are roughly fifty percent richer than those who report Democratic affiliation).

We informed subjects upfront that the survey was part of an academic study. Given academia's left-wing reputation, one might worry that social-desirability bias would lead subjects to give more pro-redistribution answers (see, e.g., Bernardi, 2006, Dalton and Ortegren, 2011). In our setting, such concerns may be limited, as earlier research suggests that web-based surveys may be less prone to social desirability bias than traditional in-person interviews (Kreuter et al., 2008). We further tried to mitigate any such concerns by emphasizing early in the survey instructions that we sought individuals' genuine responses, explaining that: "You are invited to participate in an opinion survey. There are no right or wrong answers [emph. in original]."

We also asked respondents directly about whether they perceived some left-wing, rightwing or other sort of bias in our survey, though we only thought to do so in the very last experimental session (on August 7th, 2014, the session for "real stakes"). Nonetheless, results from this session suggest very few respondents felt the survey was biased. Roughly 7.6 and 2.7 percent, respectively, said it was biased in a "politically liberal" or "politically conservative" manner, another 2.7 percent said it was biased in some other manner, with the remaining 87 percent saying they did not detect any bias. While these cross-tabs cannot speak to whether subjects were biased in some subconscious manner, we are somewhat reassured that social desirability bias is unlikely to be large. 


\subsection{Data sample}

Table 1 provides details on all MTurk workers from all sessions that we conducted, comparing them to the (weighted) population of adults sampled in the 2014 General Social Survey. Consistent with past work using MTurk, we find that younger, male, and college-educated subjects are over-represented in our sample. ${ }^{9}$ Also consistent with prior work, household incomes are relatively low among MTurk workers. On the social and political variables that may directly relate to distributional preferences, our sample is more likely to have voted than the average GSS respondent, and slightly more apt to believe that government should reduce income differences through redistribution. Relatedly, MTurk subjects are also more likely to believe that success is a matter of luck than hard work, relative to GSS respondents. In a robustness check we present results reweighted to be reflective of the GSS population based on age, gender, income, and belief that the government should reduce income differences.

Table 2 provides a longer list of covariates for the MTurk sample.

\subsection{Notation and definitions}

Before proceeding to our main specifications and results, it is useful to provide some notation and define several terms to facilitate our exposition in the next section.

We define several variables that capture differences between the two income distributions. Let Income $_{p}^{D}$ be the income of the individual in position $p=1, \ldots 7$ in Society $D \in\{A, B\}$. Recall that position is increasing in income, so the poorest person in a seven-person distribution has position 1 and the richest person has position 7 .

We define Diff Income Is $_{p}$ as the income for position $p$ in Society $B$ minus the income for position $p$ in Society $A$. The preferences described in Section 2 predict that subjects will make decisions based on absolute difference in income for $p$ in $B$ versus $A$, so that Society $B$ is preferred to Society $A$ if and only if:

$$
\sum_{j=p_{i}+1}^{7} \alpha_{j, p_{i}} \text { Diffincome }_{j}-\sum_{j=1}^{p_{i}-1} \beta_{j, p_{i}} \text { Diff Income }_{j}>0
$$

As a specific example, consider the income distributions presented in Figure 1. The subject is in position 4 , with income of $\$ 82,944$, while the position 5 incomes are $\$ 111,319$ and $\$ 129,418$ for Societies $A$ and $B$ respectively. Since the position 5 income is higher in Society $B$ than Society $A$, Diff Income $_{5}=18,099>0$. To assess whether Society $A$ is preferred to

\footnotetext{
${ }^{9}$ Unfortunately our post-experiment survey did not ask for respondents' race, but other studies have found that MTurk workers are less likely to be minorities than the U.S. average.
} 
Society $B$ overall, we need to assign utility weights for each position in the case that individual $i$ is in position 4. Suppose, for example, that the weights for positions one through three are $1 / 8,1 / 4,1 / 2$ and for positions five through seven they are $1 / 2,1 / 4,1 / 8$ (so that inequality aversion decreases with distance from the subject in the distribution). Summing over the differences in incomes for each position, weighted by their respective weights, we find that the expression above sums to 8439.63 so that $U_{i}(\operatorname{Society} B)>U_{i}(\operatorname{Society} A)$.

We also employ an alternative measure of differences in income inequality between the two distributions that is not sensitive to the widely differing income ranges at different positions in the distribution. Specifically, instead of Diff Income, we look at a binary indicator variable that captures simply whether the income for position $p$ is higher in Society $B$ than in Society A. That is,

$$
\text { SignIncome }_{p}= \begin{cases}1 & \text { if } \text { Income }_{p}^{B}-\text { Income }_{p}^{A}>0 \\ 0 & \text { otherwise }\end{cases}
$$

Note that for expositional parsimony we engage in some abuse of notation by calling this variable SignIncome, when in fact it takes values of 0 and 1 , not -1 and 1 .

Finally, given our interest in testing whether respondents focus on those closer to them in the distribution, we also define measures that are relative to the subject's own position. We thus define, for subject in position $p$, Diff Income ${ }^{+1}=$ Diff Income $_{p+1}$. So, in the preceding example (illustrated in Figure 1), Dif Income $^{+1}=18,099 .{ }^{10}$

Past work has found that subjects often try to maximize total surplus, so it is natural to consider total income as a control in some specifications (though its introduction into the Fehr-Schmidt model is not without complications - we return to this point below). We define Diff Surplus as the difference in total income of all individuals in Society $B$ versus Society A:

$$
\text { DiffSurplus }=\sum_{r=1}^{7} \text { Income }_{r}^{B}-\sum_{r=1}^{7} \text { Income }_{r}^{A} .
$$

Similarly, we generate an indicator variable, SignSurplus, that denotes whether Society $B$ has greater aggregate income than Society $A$.

\footnotetext{
${ }^{10}$ We similarly define DiffIncome ${ }^{+2}=$ Diff Income $_{p+2}$, DiffIncome Dif $^{-1}=$ Diff Income $_{p-1}$, and Diff Income I $^{-2}=$ Diff Income In $_{2}$.
} 


\section{Results}

We begin by presenting visual displays of the data to depict how subjects decide between the two distributions, and then proceed to more formal regression results. We present an initial set of results that mirror the fully flexible specification in equation (2), which we will use in large part to motivate the more parsimonious specification that we present in our main regression tables.

\subsection{Graphical evidence}

We begin by exploring how subjects' decisions depend on income differences between the two distributions, independent of the subject's own position. In Figure 3 we show the results from the following specification:

$$
\text { Choose }_{i k}^{B}=\alpha+\sum_{q=1}^{7} \lambda_{q} \text { SignIncome }_{q, i k}+\boldsymbol{P}_{\boldsymbol{i k}}+\epsilon_{i k}
$$

which includes seven fixed effects for the position held by $i$ in decision $k\left(\boldsymbol{P}_{\boldsymbol{i k}}\right)$. Choose $e_{i k}^{B}$ is an indicator variable for subject $i$ in iteration $k$ of the experiment choosing Society $B$, and SignIncome $_{q, i k}$ is an indicator variable for position $q$ having a higher income value in Society $B$. Each coefficient $\lambda_{q}$ can be interpreted as the percentage point increase in likelihood that the subject selects Society $B$ if the income of position $q$ is higher in $B$. We also graph 95 percent confidence intervals, using standard errors clustered by subject.

In general, inequality aversion will lead subjects to pick distributions in which low positions have relatively high incomes. The graph clearly indicates a concern for raising the income of the poorest member of society: the probability of selecting Society $B$ is nearly 30 percentage points higher if the income in its lowest position is higher than in Society $A$. We also observe an important role for the highest income - subjects are more than 10 percentage points more likely to select Society $B$ if its richest individual has a lower income. For positions two through six, we observe precisely estimated zero coefficients indicating that, on average, incomes in these positions had no effect on subjects' decisions. Overall, our findings indicate that models of inequality aversion may wish to account for extremes in income - both rich and poor - and place less emphasis on intermediate incomes.

We next explore whether subjects' choices are affected by incomes relative to their own, as would be the case in standard models of inequality aversion. We do so by allowing the coefficients in the preceding analysis to vary depending on the subject's own position in the distribution, so that for each $p \in\{1,2, \ldots, 7\}$, we estimate the following equation via OLS: 


$$
\text { Choice }_{i k}^{B}=\alpha+\sum_{q \neq p} \eta_{q}^{p} \text { SignIncome }_{q, i k}+\epsilon_{i k}
$$

The estimation in each case is for all decisions $k$ made by subject $i$ in which she was assigned position $p$ in the income distribution. Similar to the preceding figure, the $\eta_{q}^{p}$ coefficients tell us whether subjects are more or less likely to choose a distribution that is favorable to position $q$ when subjects are themselves in position $p$.

We plot the estimated $\eta_{q}^{p}$ coefficients separately for each value of $p$, across the seven panels of Figure 4. As expected given the patterns in Figure 3, regardless of assigned rank, for all $p>1, \eta_{1}^{p}$ is large and positive, indicating that subjects in all positions put considerable weight on raising the income of the least well off individual (recall, $\eta_{1}^{p}$ is not defined for $p=1$ ). We similarly observe that for all $p<7 \eta_{7}^{p}$ is negative across all panels, indicating a general desire to "soak the rich."

The only other case for which we observe a significant deviation from zero across all panels is for the position directly above the subject's own. In every panel, the "one above" coefficient is negative and significantly different from zero at the five-percent level. No other coefficient in positions two through six is significant across all panels, regardless of its position relative to the subject. To emphasize the importance that subjects place on "one above" incomes in particular, in panels (a) - (d) we can compare concern for the incomes of those one and two positions above the subject's own. In each case, we observe that for each own-position $p, \eta_{p+1}^{p}<\eta_{p+2}^{p}$ (significant at least at the ten-percent level in all cases). That is, subjects are averse to picking the distribution in which the individual in position $p+1$ has a relatively high income, whereas the incomes of individuals in position $p+2$ are relatively unimportant. (In panel (e), we observe that $\eta_{p+1}^{p}>\eta_{p+2}^{p}$, but this comparison conflates the effects of topmost and local competitiveness.)

Other than these patterns, which indicate aversion to inequality at the extremes as well as local competitiveness, relative incomes in other positions are uncorrelated with subjects' choices. This pattern is difficult to reconcile with standard models of distributional preferences that emphasize aggregate differences or raising only extremely low incomes.

\subsection{Regression results}

Motivated by the preceding results, we present our main regression estimates in the following parsimonious specification.

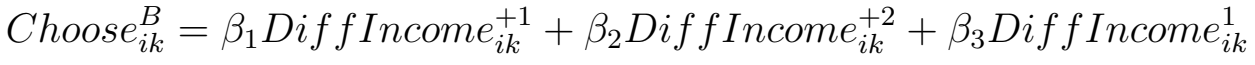

$$
\begin{aligned}
& +\beta_{4} \text { Diff Income } e_{i k}^{7}+\lambda X_{i k}+e_{i k},
\end{aligned}
$$


where $X_{i k}$ are covariates related to subject $i$ or iteration $k$ (e.g., subject fixed effects, iteration fixed effects), which we vary to probe robustness. This specification focuses our analysis on the patterns that emerged in the previous section, allowing us to explore the robustness of inequality aversion toward top, bottom, and "one above" incomes across a range of specifications (we include Diff Income ${ }^{+2}$ to ensure that, in looking at "just above" incomes, we distinguish local competition from general aversion to disadvantageous inequality). For these analyses, we pool all decisions in which subjects held positions two through five, so that all covariates are defined. Recall that we pool the first two experimental sessions, which constitute the "baseline" experiment before we explore variants of the experiment. Throughout, monetary values are expressed in units of $\$ 10,000$ to make the output tables more readable. The coefficient on Diff Income ${ }^{1}$, for example, may be interpreted as the percentage point increase in the probability of selecting Society $B$ if the income of the poorest individual in Society $B$ increases by $\$ 10,000$ relative to the income of the poorest individual in Society $A$.

We present the results from this specification in Table 3. In column (1) we show the results including the set of Diff Income variables. The coefficients on Diff Income $e^{1}$ and Dif f Income ${ }^{7}$ are positive and negative, respectively, and both highly significant $(p<0.0001$ in both cases). The coefficient on Diff Income $e^{1}$ is 0.195 , implying that a one standard deviation increase in Diff Income ${ }^{1}$ (0.688) leads to a 13.4 percentage point greater probability that a subject selects Society $B$. The coefficient on Diff Income ${ }^{7},-0.0426$, implies that a one standard deviation increase in Diff Income ${ }^{7}$ (1.231) leads to a 5.2 percentage point lower probability that a subject selects Society $B$. We also find a strong local competition effect: we estimate that $\beta_{1}=-0.0371$, whereas $\beta_{2}=-0.000224$. The difference is significant at the one percent level.

In column (2) we include 10 question-order (iteration) fixed effects, which has little effect on our estimates of the coefficients on the Dif f Income variables. Column (3) includes fixed effects for the subject's position in the income distribution. Column (4) excludes subjects who completed the experiment very rapidly (less than 4 minutes). In all cases, the coefficients on the Diff Income variables are virtually unchanged.

In Appendix Table A2 we present results that reweight observations to be reflective of the GSS population based on age, gender, income, and belief that the government should reduce income differences. Results remain unchanged. While our preferred sample drops anyone in the second session who already took the survey experiment in the first session, Appendix Table A3 shows the results are robust to keeping these repeat-takers.

As Engelmann (2012) emphasizes, introducing a surplus term into the standard FehrSchmidt model makes the coefficients difficult to interpret. For example, suppose we control for the change in total surplus in equation 6 . Then, the effects of DiffIncome ${ }^{1}$, 
Diff Income $^{7}$ and DiffSurplus could be re-interpreted as the effects of DiffIncome ${ }^{1}$, Diff Income $e^{7}$ and the total change in all other positions (as $\sum_{p}$ Diff Income $_{p}=$ DiffSurplus). Put differently, holding DiffSurplus constant (as we implicitly do when we control for it) while increasing Diff Income $e^{p}$ requires that some Diff Income $e^{p^{\prime}}$ for $p^{\prime} \neq p$ must decrease. Nonetheless, for the sake of completeness, we include the change in surplus in Appendix Table A4. Our coefficients of interests remain unchanged. In particular, the coefficient on Diff Income ${ }^{1}$ barely falls, suggesting that little of the observed preference for raising the income of the poorest person is explained by a desire to raise total surplus.

In a similar vein, we include the difference in Gini coefficients between the two distributions as a control in Appendix Table A5, to ensure that the emphasis we document over Diff Income ${ }^{1}$, DiffIncome $e^{7}$, and DiffIncome ${ }^{+1}$ are distinguishable from a general distaste for inequality. Again, we find that the coefficients on our variables of interest are largely unchanged.

In Table 4 we repeat our analyses from Table 3, replacing the Dif f Income variables with SignIncome variables (recall, a dummy for whether a given value in Distribution $B$ is larger than that in $A$ ). The results are qualitatively similar, but are more readily interpretable. Consider the estimates in column (1). The coefficients on SignIncome ${ }^{1}$, SignIncome ${ }^{7}$, and SignIncome $e^{+1}$ are $0.299,-0.107$, and -0.0873 respectively (all significant at the one-percent level), whereas the coefficient on SignIncome ${ }^{+2}$ is very close to zero. These results indicate that a subject is nearly thirty percentage points more likely to select Society $B$ if the income of the poorest individual in that distribution is higher than the income of the poorest individual in Society $A$. The coefficient estimates also indicate a significant concern for reducing the incomes of individuals in the highest position and those in the position immediately above the subject's own. These latter two effects are of comparable magnitudes, and about a third as large as the effect of the poorest individual's income.

\subsection{Results from companion experiments}

So far we have shown that the results from our main experimental sessions are robust to a wide range of specifications. We now document the results from the companion experiments mentioned earlier to assess the robustness of our results to changing various aspects of the experimental design.

After our two main experimental sessions, we conducted six additional experiments that significantly changed some property of the original experiment.

1. The OV ("own variation") experiment. This experiment allows the subject's own income to vary between distributions $A$ and $B$. However, in both distributions he is in 
the same rank.

2. The NP ("nine player") experiment. This experiment tests whether the main results are robust to increasing the number of members in each distribution. For this experiment, we begin with an interval of $\$ 10,000-\$ 20,000$, with the increment increasing by $\$ 4,000$ for each interval, so that $\$ 202,000-\$ 244,000$ is the highest interval.

3. The HI ('high inequality") experiment. In the "high inequality" version, the lowest income range was $\$ 10,000-\$ 15,000$, with the income ranges increasing by $\$ 10,000$ at each increment (so the top range was $\$ 190,000-\$ 255,000$ ).

4. The VI ("very high inequality") experiment. In the "very high inequality" version, the income ranges increased by $\$ 15,000$ at each increment (so the top range was $\$ 265,000$ $\$ 360,000)$.

5. The AF ("alternative framing") experiment. In this version, we provide an alternative presentation of the data, with the subject's own income presented to the far left of each panel in every decision. See Figure 2. The purpose of this version of the experiment was specifically to explore whether the local competition effect was attenuated by drawing subjects' attention away from the area of the graph immediately around their own incomes.

6. The RS ("real stakes") experiment. In this version, subjects were informed that, with 10 percent probability, one of their rounds would be implemented for a scaled down version (with each value divided by 10,000) of the chosen income distribution.

In Table 5 we repeat the specification from column (1) of Table 3 for these companion experiments. (For completeness, a full set of results paralleling those presented in Table 3 are available for each additional session in a series of Appendix tables.) The first two columns in fact show the results from our main sample, but separately by session: first the "absolute differences" session and then the "percentage differences" session. We show these results to ensure that the results we report in Table 3 are not driven by just one of the two sessions.

Across all sessions, the coefficients on Dif f Income ${ }^{1}$ and Diff Income $e^{7}$ are quite stable, indicating that aversion to inequality at both the high and low extremes of the income distribution is robust to the type of distribution, its presentation, as well as the introduction of payoff consequences for subjects' choices. Note that these effects are somewhat smaller in column (3), suggesting that variation in own income crowds out interest in other aspects of the distribution (and, not surprisingly, the R-squared term in this column is much larger, as own income has very large predictive power). 
Our estimate of local competitiveness, as captured by $\beta_{1}-\beta_{2}$, is consistently negative and significantly different from zero in the sessions that allow the subject's own income to vary (column 3), increase the number of players to nine (column 4, in which case topmost inequality aversion is captured by Diff Income ${ }^{9}$ ), vary the extent of inequality (columns 5 and 6), and present the distributions using an alternative formatting in which the subject's own income was placed separately at the left side of each distribution (column 7).

In general, framing effects are always a concern in a setting such as ours. Our distributions confront subjects with a good deal of information, leading to concerns that cognitively overloaded subjects will focus on particularly salient parts of the distribution - the extremes and those very close to them. Most compellingly, we find the robustness to the "alternative framing" (AF) variant to be encouraging evidence that concern for immediate income neighbors does does not merely capture salience: in the AF session, the placement of the red bar indicating own income would seem to distract attention from the "local" part of the distribution, yet we find that subjects still lower the income of the individual above them. Similarly, the "nine player" (NP) variant should lead to even more overload, as we have increased the population of the distribution by over one-fourth. If information overload were driving our results, we might expect to see larger coefficients on our variables of interest in this session. Instead, we see that for the top and bottom incomes, the coefficients in the NP session fall in the middle of the range defined by the full set of experiments (while the local competition effect is on the larger side, the second largest of the eight sessions). Our takeaway is that changing the amount of information confronting subjects as well as the way it this information was presented has little effect on the overall patterns we observe in our data.

\subsection{Understanding differences in the real-stakes versus hypothetical sessions}

Our three major results - top- and bottom-most inequality aversion and local competitionreplicate in seven of the eight sessions, and top- and bottom-most inequality aversion replicate in all eight sessions. However, we find a weakened local competition effect in the real stakes session (column 8). Individuals are still more likely to choose the distribution with the lower income for the person directly above, though this result is no longer significant. Moreover, when we compare this coefficient to that of the person two positions above, the difference, while still of the predicted sign, is much smaller in magnitude and no longer significant.

The prior literature provides little guidance on this matter. Camerer and Hogarth (1999), in particular, provide a meta-analysis of 74 studies that have no, low or high-powered incentives. They find that the effect of real stakes depends on the experimental task. ${ }^{11}$ None

\footnotetext{
${ }^{11}$ Some more recent experiments since the meta-analysis was published focus specifically on
} 
of these experiments, however, concern the types of distributive principles that we explore here. Moreover, we are also intentionally evoking the actual income distribution, which most experiments do not do. The only redistribution experiment we know of that compares hypothetical and real stakes is Charité et al. (2015b), who find similar results in a modified dictator game with and without real stakes, though that experiment did not try to frame outcomes in terms of actual, real-world income distributions.

The differing results across real stakes versus hypothetical treatments potentially raise deeper methodological questions on the measurement of distributional preferences in lab experiments. In particular, we are interested in studying distributional preferences over total income or wealth, so that it is naturally impossible to implement subjects' choices in practice. As a result, when we impose payoff consequences we may substantively shift the distributive principles that subjects invoke in making their decisions. That is, subjects may have in mind the fairness principles toward a society's income distribution overall when making choices without direct payoff consequences. But when they are told that some specific, rather arbitrary handful of actual people (those MTurk workers we are rewarding with $\frac{1}{10,000}$ of these "real-world" income values) will experience these payoffs, they may invoke different principles.

It is also possible that individuals consider general-equilibrium effects when they think of society's income distribution. For example, the local competition effect could, in theory, be driven by worries that if individuals slightly richer than oneself become even richer, goods one is most likely to purchase become more expensive via increased demand. (Obviously, general-equilibrium effects are negligible when only seven people are affected.)

Another challenge in applying results from small-stakes lab experiments to preferences about society's income distribution is that marginal utility of income enters more into the latter framing than in the former. In the classic inequality-aversion set up, utility is linear in own-income, an approximation that is likely innocuous for the small-stakes settings in which it is typically tested. ${ }^{12}$ If subjects were highly sensitive to concerns about the diminishing marginal utility of a dollar, we might expect that the coefficients on the tail incomes in the "real stakes" version to be smaller in magnitude than in the other sessions (since the amount of money involved would have trivial effects on the marginal utility of income in the "real

comparing behavior with and without payoff consequences, but again find mixed results. Further, none of these recent studies invokes the sort of distributive concerns that are our focus in this paper. See, for example, Etchart-Vincent and l'Haridon (2011) and Beattie and Loomes (1997).

${ }^{12}$ It has been observed, however, that lab subjects may behave as if variation in small stakes lead to diminishing marginal utility of money. See Rabin (2000), who attribute the large extent of apparent risk-aversion that subjects display in choosing whether to participate in lotteries to loss-aversion. 
stakes" version, but potentially large effects in the others). Comparing the "real stakes" session to the other versions in Table 5 the coefficients on the top and bottom incomes are generally quite similar (the coefficients found in the "real stakes" version are roughly at the midpoint of the range formed by the full set of sessions). So, taken literally, our results seem to suggest that these concerns were not paramount to our subjects. However, we find this distinction (between true inequality aversion and beliefs about the diminishing marginal utility of money) to be a very interesting question for future work.

Our paper has certainly not bridged the gap between distributive preferences over the actual income distribution and those that can be tested in a real stakes setting (which will naturally involve small stakes), but we hope that our findings provide a starting point for future experiments that, like ours, attempt to further our understanding of both sets of preferences.

\subsection{Heterogeneity in Distributional Preferences}

In our final set of analyses, we explore the extent to which our estimated effects from equation (6) vary systematically with political or self-stated distributional preferences, using our main sample. In columns (1) and (2) of Table 6, we compare the decisions of self-identified Democrats and Republicans (many subjects identified as independents, which is why the total sample is smaller). We conjecture that, given the Republican Party platform in recent decades of lowering taxes, its supporters will be less apt to choose distributions that reduce inequality. Consistent with this view, we find that Republicans are less likely to choose distributions with lower incomes in the top position (i.e., the coefficient on Diff Income ${ }^{7}$ is less negative in column (2) than in column (1)). Similarly, Republicans are less likely to select distributions with higher incomes in the lowest position. But we observe no difference between the two subsamples in their attitudes toward incomes of those directly above them — in both instances we observe a strong local competition effect.

In columns (3) and (4) we divide the sample based on responses to the question, "Do you feel that the distribution of income and wealth in the U.S. today is fair or should be more evenly distributed among a larger portion of the population?" Those in col. (3) take the more redistributive position that income should be more evenly divided, whereas those in col. (4) take the position that redistribution is not needed. In general, this cut of the data reveals starker differences in preferences than we saw in the first two columns. The coefficient on the poorest person's income is 67 percent larger for those in col. (3) than in col. (4). Even more striking differences between the two groups emerge in how they view the income of the richest person. For those who feel no more redistribution is needed in the U.S., the income of the richest person has no predictive power over which distribution is chosen (though the 
coefficient is negative). The corresponding coefficient for those who feel more redistribution is needed is over seven times larger in magnitude, negative and highly significant. The fact that the two groups differ far more on their views on the incomes of the rich than their views on the incomes of the poor may reflect the oft-stated conservative principle that inequality per se is not a concern relative to ensuring decent opportunities for the poor. ${ }^{13}$

Interestingly, however, despite these disparate views on incomes at the tails of the distribution, we see no substantial difference in the coefficients on Diff Income ${ }^{+1}$ and Diff Income $e^{+2}$. Overall, we take these findings as an indication of that the local competition effect may be quite distinct from preferences toward income inequality in general, which tend to focus more on the best- and worst-off members of society.

In Appendix Table A14 we show the same heterogeneity analysis for the session in which own income was varied. We find broadly similar patterns: those who feel that income should be more evenly distributed in the U.S. are also willing to give up more of their money to help the poorest person or to lower the income of the richest person, relative to those who feel the current U.S. distribution is fair. We view these results as reassuring checks on the validity of our main results. In general, we find similar patterns across all of our companion experiments, but in the interest of space do not report these results.

Finally, in Appendix Table A15, we explore whether the patterns we report in our main result differ by subject income, age, gender, or education. For the first two subject characteristics, we split the sample at the median. Across all columns, we find remarkable stability in the local competition effect-the coefficients in each pair are near-identical. While we find some differences in top-most and bottom-most inequality aversion (e.g., women exhibit somewhat greater top-most inequality aversion than men), the overall patterns are quite consistent across sample splits.

\section{Conclusion}

In this paper, we study distributional preferences in "large" (seven to nine person) groups, using a series of online experiments conducted via Mechanical Turk. We find a very robust and consistent emphasis on reducing extreme inequality: consistent with Rawlsian preferences, subjects are much more likely to select an income distribution that leads to a higher income for the poorest individual. More novel, we find a robust preference for distributions that, all else equal, have lower incomes for the richest individual, and also (in most experimental

\footnotetext{
${ }^{13}$ See, e.g., Mankiw (2013), who writes, "To the extent that our society deviates from the ideal of equality of opportunity, it is probably best to focus our attention on the left tail of the income distribution than on the right tail."
} 
sessions) a preference for reducing the incomes of individuals directly above the subject.

Our experiments were quite abstract in the sense that there was no mention of how Society $A$ might be transformed into Society $B$. Future work may wish to emphasize the role that taxes and transfers would necessarily play in comparing two hypothetical societies. Recent work has found that subjects often react differently to variation they were told was exogenous versus variation they were told was driven by taxation. For example, Kessler and Norton (2016) find that labor supply (in the form of real effort) drops more when subjects are told that a tax has been taken out of an experimental wage than when the wage is merely lowered (even though the change in the effective wage was the same).

On the other hand, while our work is motivated by a desire to better understand attitudes toward income inequality for the U.S. overall, the decisions confronting our subjects may be relevant for inequalities in more intimate groups. For example, our results may thus be applied to understanding (and devising empirical tests for) attitudes toward pay inequalities within companies or other organizations.

We hope that our experimental findings can provide some guidance on how individuals weight income gaps between themselves and others in particular positions in a given distribution. While our results, taken from a combination of real stakes and hypothetical experiments, should be interpreted with caution, we hope that it will spur further work to enrich our understanding of how individuals conceive of inequality in larger groups that have more direct relevance for the types of redistributive decisions confronted by society. 


\section{References}

Ackert, Lucy F, JORGE MARTINEZ-VAZQUEZ, and Mark Rider, "Social preferences and tax policy design: some experimental evidence," Economic Inquiry, 2007, 45 (3), 487-501.

Almas, Ingvild, Alexander W. Cappelen, Erik O. Sorensen, and Bertil Tungodden, "Fairness and the Development of Inequality Acceptance," Science, 2010, 328, 1176-1178.

Andreoni, James and John Miller, "Giving According to GARP: An Experimental Test of the Consistency of Preferences for Altruism," Econometrica, 2002, 70 (2), 737-753.

Beattie, Jane and Graham Loomes, "The impact of incentives upon risky choice experiments," Journal of Risk and Uncertainty, 1997, 14 (2), 155-168.

Beckman, Steven R, John P Formby, and W James Smith, "Efficiency, equity and democracy: Experimental evidence on Okuns leaky bucket," in "Inequality, welfare and income distribution: Experimental approaches," Emerald Group Publishing Limited, 2004, pp. 17-42.

Bernardi, Richard A, "Associations between Hofstedes cultural constructs and social desirability response bias," Journal of Business Ethics, 2006, 65 (1), 43-53.

Bolton, Gary E and Axel Ockenfels, "ERC: A Theory of Equity, Reciprocity, and Competition," American Economic Review, 2000, pp. 166-193.

Camerer, Colin F and Robin M Hogarth, "The Effects of Financial Incentives in Experiments: A Review and Capital-Labor-Production Framework," Journal of Risk and Uncertainty, 1999, $19(1), 7-42$.

Cappelen, Alexander W, Trond Halvorsen, Erik $\varnothing$ Sørensen, and Bertil Tungodden, "Face-saving or fair-minded: What motivates moral behavior?," Journal of the European Economic Association, 2017, 15 (3), 540-557.

Charité, Jimmy, Raymond Fisman, and Ilyana Kuziemko, "Reference Points and Redistributive Preferences: Experimental Evidence," Technical Report, National Bureau of Economic Research 2015.

_ , _ , and _ , "Reference Points and Redistributive Preferences: Experimental Evidence," Technical Report, National Bureau of Economic Research 2015.

Charness, Gary and Matthew Rabin, "Understanding Social Preferences with Simple Tests," Quarterly Journal of Economics, 2002, 117 (3), 817-869. 
Dalton, Derek and Marc Ortegren, "Gender differences in ethics research: The importance of controlling for the social desirability response bias," Journal of Business Ethics, 2011, 103 (1), 73-93.

Durante, Ruben, Louis Putterman, and Joël Van der Weele, "Preferences for redistribution and perception of fairness: An experimental study," Journal of the European Economic Association, 2014, 12 (4), 1059-1086.

Engelmann, Dirk, "How not to extend models of inequality aversion," Journal of Economic Behavior \& Organization, 2012, 81 (2), 599-605.

- and Martin Strobel, "Inequality Aversion, Efficiency, and Maximin Preferences in Simple Distribution Experiments: Comment," American Economic Review, 2004, 96 (5), 1906-1911.

Etchart-Vincent, Nathalie and Olivier l'Haridon, "Monetary incentives in the loss domain and behavior toward risk: An experimental comparison of three reward schemes including real losses," Journal of risk and uncertainty, 2011, 42 (1), 61-83.

Farhi, Emmanuel and Xavier Gabaix, "Optimal taxation with behavioral agents," Technical Report, National Bureau of Economic Research 2015.

Fehr, Ernst and Klaus M. Schmidt, "A Theory Of Fairness, Competition, and Cooperation," Quarterly Journal of Economics, 1999, 114 (3), 817-868.

Fisman, Raymond, Shachar Kariv, and Daniel Markovits, "Individual Preferences for Giving," American Economic Review, 2007, 97 (5), 1858-1876.

Forsythe, Robert, Joel Horowitz, N. S. Savin, and Martin Sefton, "Fairness in Simple Bargaining Games," Games and Economic Behavior, 1994, 6 (3), 347-369.

Holt, Charles A and Susan K Laury, "Risk aversion and incentive effects," American Economic Review, 2002, 92 (5), 1644-1655.

Kahneman, Daniel, Jack Knetsch, and Richard Thaler, "Fairness and the Assumptions of Economics," Journal of Business, 1986, 59 (4), S285-S300.

Kessler, Judd B and Michael I Norton, "Tax aversion in labor supply," Journal of Economic Behavior \& Organization, 2016, 124, 15-28.

Krawczyk, Michał, "A glimpse through the veil of ignorance: Equality of opportunity and support for redistribution," Journal of Public Economics, 2010, 94 (1), 131-141.

Kreuter, Frauke, Stanley Presser, and Roger Tourangeau, "Social Desirability Bias in CATI, IVR, and Web Surveys: The Effects of Mode and Question Sensitivity," Public Opinion Quarterly, 2008, 72 (5), 847-865. 
Kuziemko, Ilyana, Michael I Norton, Emmanuel Saez, and Stefanie Stantcheva, "How elastic are preferences for redistribution? Evidence from randomized survey experiments," The American Economic Review, 2015, 105 (4), 1478-1508.

Lockwood, Benjamin B, "Optimal Income Taxation with Present Bias," 2016.

Luttmer, E.F.P., "Neighbors as negatives: Relative earnings and well-being," The Quarterly Journal of Economics, 2005, 120 (3), 963-1002.

Mankiw, N. Gregory, "Defending the One Percent," Journal of Economic Perspectives, September 2013, 27 (3), 21-34.

Norton, Michael I and Dan Ariely, "Building a Better America-One Wealth Quintile at a Time," Perspectives on Psychological Science, 2011, 6 (1), 9-12.

Rabin, Matthew, "Risk aversion and expected-utility theory: A calibration theorem," Econometrica, 2000, 68 (5), 1281-1292.

Saez, Emmanuel and Stefanie Stantcheva, "Generalized social marginal welfare weights for optimal tax theory," The American Economic Review, 2016, 106 (1), 24-45.

Schumacher, Heiner, Iris Kesternich, Michael Kosfeld, and Joachim Winter, "One, Two, Many-Insensitivity to Group Size in Games with Concentrated Benefits and Dispersed Costs," The Review of Economic Studies, forthcoming. 
Table 1: Basic summary statistics in mTurk sample compared to GSS sample

\begin{tabular}{lcc}
\hline & $(1)$ & $(2)$ \\
& MTurk sample & GSS sample \\
\hline Female & 0.436 & 0.545 \\
& $(0.496)$ & $(0.498)$ \\
Age & 32.42 & 47.46 \\
& $(11.00)$ & $(17.24)$ \\
Has at least college education & 0.572 & 0.316 \\
& $(0.495)$ & $(0.465)$ \\
Household income & 61.86 & 81.00 \\
& $(168.8)$ & $(80.64)$ \\
Voted in last US presidential & 0.715 & 0.639 \\
election & $(0.451)$ & $(0.480)$ \\
Supports gov't redistribution & 4.571 & 4.244 \\
(scale 1-7) & $(1.908)$ & $(2.062)$ \\
Thinks hard work most & 0.423 & 0.707 \\
important to get ahead & $(0.494)$ & $(0.455)$ \\
\hline Observations & 6725 & 2538 \\
\hline
\end{tabular}

Notes: Col. 1 includes all sessions of the experiment. Only subjects who completed all 10 iterations are included. For re-takers, they are included only the first time they took the survey. Col. 2 includes all adults in the 2014 General Social Survey (weighted with the provided individual-level weights). Income refers to household income (in units of $\$ 1,000$ ). 
Table 2: Full summary statistics in mTurk sample

\begin{tabular}{lcc}
\hline & mean & sd \\
\hline Age & 32.49 & $(11.04)$ \\
Female & 0.42 & $(0.49)$ \\
Has at least college education & 0.57 & $(0.49)$ \\
Household income & 61.69 & $(167.00)$ \\
Participated in real stakes round & 0.11 & $(0.31)$ \\
Assets & 117.44 & $(280.82)$ \\
Liabilities & 49.94 & $(87.65)$ \\
Minutes taken to complete the survey & 8.26 & $(12.30)$ \\
Voted in last US presidential election & 0.71 & $(0.46)$ \\
Affiliated with Democratic party & 0.37 & $(0.35)$ \\
Affiliated with Republican party & 0.15 & $(0.43)$ \\
More redistribution & 0.75 & $(0.50)$ \\
Too many rich & 0.44 & \\
\hline Observations & 6882 &
\end{tabular}

Notes: Summary statistics include observations from all sessions of the experiment. Only subjects who completed all 10 iterations are included. For re-takers, they are included only the first time they took the survey. Income refers to household income (in units of $\$ 1,000$ ). Assets and Liabilities refer, respectively, to the approximate total value of assets and liabilities (in units of $\$ 1,000)$. More Redistribution is a binary variable that denotes whether respondents feel that the distribution of income and wealth in the U.S. today is fair (0) or should be more evenly distributed among a larger portion of the population (1); Too Many Rich indicates whether respondents feel that there are too many rich people in the U.S. All other variables are self-explanatory. 
Table 3: Bottom, Topmost and Local Inequality Aversion in the Main Sample

\begin{tabular}{lcccc}
\hline & \multicolumn{4}{c}{ Dep. var: Chose Distribution B over A } \\
\cline { 2 - 5 } & $(1)$ & $(2)$ & $(3)$ & $(4)$ \\
\hline Diff Income $^{+1}$ in B vs. A & $-0.0371^{* * *}$ & $-0.0372^{* * *}$ & $-0.0372^{* * *}$ & $-0.0388^{* * *}$ \\
& {$[0.00415]$} & {$[0.00416]$} & {$[0.00416]$} & {$[0.00438]$} \\
Diff Income $^{+2}$ in B vs. A & -0.000224 & -0.000329 & -0.000328 & -0.000106 \\
& {$[0.00365]$} & {$[0.00365]$} & {$[0.00365]$} & {$[0.00382]$} \\
Diff Income $^{1}$ in B vs. A & $0.195^{* * *}$ & $0.196^{* * *}$ & $0.196^{* * *}$ & $0.200^{* * *}$ \\
& {$[0.00662]$} & {$[0.00662]$} & {$[0.00662]$} & {$[0.00690]$} \\
Diff Income $^{7}$ in B vs. A & $-0.0426^{* * *}$ & $-0.0425^{* * *}$ & $-0.0425^{* * *}$ & $-0.0442^{* * *}$ \\
& {$[0.00407]$} & {$[0.00407]$} & {$[0.00407]$} & {$[0.00431]$} \\
\hline Above Two/One Diff. & $.03691^{* * *}$ & $.03691^{* * *}$ & $.03684^{* * *}$ & $.03866^{* * *}$ \\
Question-Order FE & No & Yes & Yes & Yes \\
Position & No & No & Yes & Yes \\
Ex. short duration & No & No & No & Yes \\
Observations & 14515 & 14515 & 14515 & 13229 \\
R2 & 0.103 & 0.103 & 0.104 & 0.109 \\
\hline
\end{tabular}

Notes: All regressions include robust standard errors clustered at the subject level. The sample in this table includes participants in the "Absolute Differences" and "Percentage Differences" experiments run in September 2013 (see text for details). Only subjects who completed all 10 iterations are included ${ }^{*} p<0.1,{ }^{* *} p<0.05,{ }^{* * *} p<0.01$. In all specifications, monetary values are expressed in units of $\$ 10,000$ to make the table more readable. Diff Income ${ }^{+1}$ is the difference in income between Societies B and A for the individual in the position directly above the subject's own. Diff Income $e^{+2}$ is similarly defined for the individual two positions above the subject.

Diff Income ${ }^{7}$ is the difference in income between Societies B and A for the richest (i.e., position 7) individual. Diff Income ${ }^{1}$ is similarly defined for the poorest individual. 
Table 4: Bottom, Topmost and Local Inequality Aversion in the Main Sample, Sign-based Results

\begin{tabular}{|c|c|c|c|c|}
\hline & \multicolumn{4}{|c|}{ Dep. var: Chose Distribution B over A } \\
\hline & (1) & $(2)$ & $(3)$ & (4) \\
\hline SignIncome $e^{+1}$ in B vs. A & $\begin{array}{c}-0.0873^{* * *} \\
{[0.00911]}\end{array}$ & $\begin{array}{c}-0.0876^{* * *} \\
{[0.00911]}\end{array}$ & $\begin{array}{c}-0.0874^{* * *} \\
{[0.00911]}\end{array}$ & $\begin{array}{r}-0.0879^{* * *} \\
{[0.00952]}\end{array}$ \\
\hline SignIncome $e^{+2}$ in B vs. A & $\begin{array}{l}-0.00199 \\
{[0.00864]}\end{array}$ & $\begin{array}{l}-0.00185 \\
{[0.00864]}\end{array}$ & $\begin{array}{l}-0.00177 \\
{[0.00864]}\end{array}$ & $\begin{array}{l}0.000842 \\
{[0.00896]}\end{array}$ \\
\hline SignIncome ${ }^{1}$ in B vs. A & $\begin{array}{l}0.299^{* * *} \\
{[0.0108]}\end{array}$ & $\begin{array}{l}0.300^{* * *} \\
{[0.0108]}\end{array}$ & $\begin{array}{l}0.300^{* * *} \\
{[0.0108]}\end{array}$ & $\begin{array}{l}0.305^{* * *} \\
{[0.0111]}\end{array}$ \\
\hline SignIncome ${ }^{7}$ in B vs. A & $\begin{array}{c}-0.107^{* * *} \\
{[0.0108]}\end{array}$ & $\begin{array}{c}-0.108^{* * *} \\
{[0.0108]}\end{array}$ & $\begin{array}{c}-0.108^{* * *} \\
{[0.0108]}\end{array}$ & $\begin{array}{c}-0.107^{* * *} \\
{[0.0112]}\end{array}$ \\
\hline Above Two/One Diff. & $.08534^{* * *}$ & $.08571^{* * *}$ & $.0856^{* * *}$ & $.0887^{* * *}$ \\
\hline Question-Order FE & No & Yes & Yes & Yes \\
\hline Position & No & No & Yes & Yes \\
\hline Ex. short duration & No & No & No & Yes \\
\hline Observations & 13605 & 13605 & 13605 & 12590 \\
\hline $\mathrm{R} 2$ & 0.109 & 0.110 & 0.110 & 0.113 \\
\hline
\end{tabular}

Notes: All regressions include robust standard errors clustered at the subject level. The sample in this table includes participants in the "Absolute Differences" and "Percentage Differences" experiments run in September 2013 (see text for details). Only subjects who completed all 10 iterations are included ${ }^{*} p<0.1,{ }^{* *} p<0.05,{ }^{* * *} p<0.01$. SignIncome ${ }^{+1}$ is an indicator variable denoting that the income of the person in the position directly above the subject is higher in Society $B$ than in Society $A$. SignIncome ${ }^{+2}$ is similarly defined for the individual two positions above the subject. SignIncome $e^{1}$ is an indicator variable denoting that the poorest individual (i.e., position 1) has a higher income in Society $B$ than in Society $A$. SignIncome ${ }^{7}$ is similarly defined for the richest (i.e., position 7) individual. 
Table 5: Results Across Experimental Treatments

\begin{tabular}{|c|c|c|c|c|c|c|c|}
\hline & \multicolumn{7}{|c|}{ Dep. var: Chose Distribution B over A } \\
\hline & $(1)$ & $(2)$ & $(3)$ & $(4)$ & $(5)$ & $(6)$ & $(7)$ \\
\hline & $\mathrm{AD}$ & $\mathrm{PD}$ & HI & VI & NP & $\mathrm{AF}$ & IC \\
\hline Diff Income $e^{+1}$ in B vs. A & $\begin{array}{c}-0.0631^{* * *} \\
{[0.00807]}\end{array}$ & $\begin{array}{c}-0.0330^{* * *} \\
{[0.00623]}\end{array}$ & $\begin{array}{c}-0.0345^{* * *} \\
{[0.00591]}\end{array}$ & $\begin{array}{c}-0.0340^{* * *} \\
{[0.00391]}\end{array}$ & $\begin{array}{c}-0.0631^{* * *} \\
{[0.00939]}\end{array}$ & $\begin{array}{c}-0.0488^{* * *} \\
{[0.00747]}\end{array}$ & $\begin{array}{c}-0.0138^{* *} \\
{[0.00674]}\end{array}$ \\
\hline 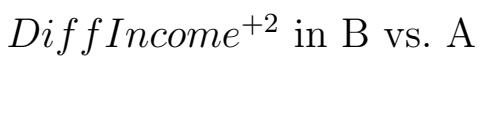 & $\begin{array}{l}-0.00666 \\
{[0.00709]}\end{array}$ & $\begin{array}{l}-0.00400 \\
{[0.00492]}\end{array}$ & $\begin{array}{c}-0.0107^{* *} \\
{[0.00427]}\end{array}$ & $\begin{array}{c}-0.00548^{*} \\
{[0.00306]}\end{array}$ & $\begin{array}{c}-0.0112 \\
{[0.00805]}\end{array}$ & $\begin{array}{l}-0.00783 \\
{[0.00587]}\end{array}$ & $\begin{array}{l}-0.00665 \\
{[0.00550]}\end{array}$ \\
\hline Diff Income ${ }^{1}$ in B vs. A & $\begin{array}{c}0.197^{* * *} \\
{[0.00878]}\end{array}$ & $\begin{array}{l}0.162^{* * *} \\
{[0.0131]}\end{array}$ & $\begin{array}{l}0.316^{* * *} \\
{[0.0406]}\end{array}$ & $\begin{array}{l}0.306^{* * *} \\
{[0.0406]}\end{array}$ & $\begin{array}{l}0.237^{* * *} \\
{[0.0234]}\end{array}$ & $\begin{array}{l}0.169^{* * *} \\
{[0.0157]}\end{array}$ & $\begin{array}{l}0.214^{* * *} \\
{[0.0140]}\end{array}$ \\
\hline Diff Income ${ }^{7}$ in B vs. A & $\begin{array}{c}-0.0687^{* * *} \\
{[0.00850]}\end{array}$ & $\begin{array}{c}-0.0407^{* * *} \\
{[0.00552]}\end{array}$ & $\begin{array}{c}-0.0638^{* * *} \\
{[0.00466]}\end{array}$ & $\begin{array}{c}-0.0387^{* * *} \\
{[0.00310]}\end{array}$ & & $\begin{array}{c}-0.0612^{* * *} \\
{[0.00645]}\end{array}$ & $\begin{array}{c}-0.0475^{* * *} \\
{[0.00586]}\end{array}$ \\
\hline DiffSurplus in B vs. A & $\begin{array}{c}0.00873^{* *} \\
{[0.00419]}\end{array}$ & $\begin{array}{c}0.00508 \\
{[0.00333]}\end{array}$ & $\begin{array}{c}0.00849^{* *} \\
{[0.00330]}\end{array}$ & $\begin{array}{c}0.00743^{* * *} \\
{[0.00223]}\end{array}$ & $\begin{array}{c}0.00823^{* *} \\
{[0.00341]}\end{array}$ & $\begin{array}{l}0.00798^{*} \\
{[0.00412]}\end{array}$ & $\begin{array}{c}0.00891^{\text {** }} \\
{[0.00388]}\end{array}$ \\
\hline chg_9 & & & & & $\begin{array}{c}-0.0588^{* * *} \\
{[0.00690]} \\
\end{array}$ & & \\
\hline Above Two/One Diff. & $.05643^{* * *}$ & $.02904^{* * *}$ & $.02383^{* * *}$ & $.02855^{* * *}$ & $.05188^{* * *}$ & $.04097^{* * *}$ & .00712 \\
\hline Round FE & No & No & No & No & No & No & No \\
\hline Position & No & No & No & No & No & No & No \\
\hline Ex. short duration & No & No & No & No & No & No & No \\
\hline Observations & 8669 & 5846 & 3631 & 4109 & 3396 & 3729 & 4523 \\
\hline $\mathrm{R} 2$ & 0.133 & 0.0644 & 0.130 & 0.102 & 0.0842 & 0.102 & 0.0965 \\
\hline
\end{tabular}

Notes: All regressions use robust standard errors clustered at the subject level. Only subjects who completed all 10 iterations are included ${ }^{*} p<0.1,{ }^{* *} p<0.05,{ }^{* * *} p<0.01$. In all specifications, monetary values are expressed in units of $\$ 10,000$ to make the table more readable. Each column presents the results of the same specification run on a different sample. AD connotes the Absolute Differences sample, PD the Percentage Differences sample, RS the Real Stakes sample, HI the High Inequality sample, NP the Nine Person Sample, VI the Very High Inequality Sample, AF the Alternative Formatting sample, and OV the Own Income Variation sample (see Section 4 in the text for more details on how the experimental treatment varies in each sample). Diff Income ${ }^{+1}$ is the difference in income between Societies B and A for the individual in the position directly above the subject's own. Diff Income ${ }^{+2}$ is similarly defined for the individual two positions above the subject. Diff Income ${ }^{1}$ is the difference in income between Societies B and A for the poorest (i.e., position 1) individual. DiffIncome $e^{7}$ (or in the case of the Nine Person version of the experiment, Diff Income ${ }^{9}$ ) is similarly defined for the richest individual. Diff Income $e^{O W N}$ is the difference in income between Societies B and A for the subject's own income. 
Table 6: Heterogeneity in Inequality Aversion

\begin{tabular}{|c|c|c|c|c|}
\hline & \multicolumn{4}{|c|}{ Dep. var: Chose Second Distribution } \\
\hline & $\begin{array}{c}(1) \\
\text { Democrat }\end{array}$ & $\begin{array}{c}(2) \\
\text { Republican }\end{array}$ & $\begin{array}{l}(3) \\
\text { Not fair distribution }\end{array}$ & $\begin{array}{c}(4) \\
\text { Fair distribution }\end{array}$ \\
\hline Diff Income $e^{+1}$ in B vs. A & $\begin{array}{c}-0.0443^{* * *} \\
{[0.00848]}\end{array}$ & $\begin{array}{c}-0.0662^{* * *} \\
{[0.0116]}\end{array}$ & $\begin{array}{c}-0.0414^{* * *} \\
{[0.00590]}\end{array}$ & $\begin{array}{c}-0.0446^{* * *} \\
{[0.00933]}\end{array}$ \\
\hline Diff Income ${ }^{+2}$ in B vs. A & $\begin{array}{l}-0.00765 \\
{[0.00667]}\end{array}$ & $\begin{array}{c}-0.00388 \\
{[0.0101]}\end{array}$ & $\begin{array}{l}-0.00696 \\
{[0.00466]}\end{array}$ & $\begin{array}{c}0.00217 \\
{[0.00800]}\end{array}$ \\
\hline Diff Income ${ }^{1}$ in B vs. A & $\begin{array}{l}0.182^{* * *} \\
{[0.0119]}\end{array}$ & $\begin{array}{l}0.131^{* * *} \\
{[0.0183]}\end{array}$ & $\begin{array}{c}0.213^{* * *} \\
{[0.00801]}\end{array}$ & $\begin{array}{l}0.118^{* * *} \\
{[0.0143]}\end{array}$ \\
\hline Diff Income ${ }^{7}$ in B vs. A & $\begin{array}{c}-0.0627^{* * *} \\
{[0.00800]}\end{array}$ & $\begin{array}{c}-0.0428^{* * *} \\
{[0.0106]}\end{array}$ & $\begin{array}{c}-0.0600^{* * *} \\
{[0.00533]}\end{array}$ & $\begin{array}{l}-0.0182^{* *} \\
{[0.00901]}\end{array}$ \\
\hline DiffSurplus in B vs. A & $\begin{array}{l}0.0136^{* * *} \\
{[0.00446]}\end{array}$ & $\begin{array}{l}0.0161^{* * *} \\
{[0.00619]}\end{array}$ & $\begin{array}{c}0.00395 \\
{[0.00307]}\end{array}$ & $\begin{array}{c}0.0120^{* *} \\
{[0.00506]}\end{array}$ \\
\hline Above Two/One Diff. & $.03666^{* * *}$ & $.06233^{* * *}$ & $.03446^{* * *}$ & $.04679^{* * *}$ \\
\hline Round FE & No & No & No & No \\
\hline Position & No & No & No & No \\
\hline Ex. short duration & No & No & No & No \\
\hline Observations & 5183 & 2293 & 10521 & 3866 \\
\hline
\end{tabular}

Notes: All regressions use robust standard errors clustered at the subject level. The sample in this table includes participants in the "Absolute Differences" and "Percentage Differences" experiments run in September 2013 (see text for details). Only subjects who completed all 10 iterations are included ${ }^{*} p<0.1,{ }^{* *} p<0.05,{ }^{* * *} p<0.01$. In all specifications, monetary values are expressed in units of $\$ 10,000$ to make the table more readable. In columns (1) and (2) regressions are run separately on the subsamples of, respectively, self-identified Democrats and Republicans. In columns (3) and (4) we divide the sample based on responses to the question, "Do you feel that the distribution of income and wealth in the US today is fair or should be more evenly distributed among a larger portion of the population?" Diff Income ${ }^{+1}$ is the difference in income between Societies B and A for the individual in the position directly above the subject's own. Diff Income $e^{+2}$ is similarly defined for the individual two positions above the subject.

Diff Income ${ }^{1}$ is the difference in income between Societies B and A for the poorest (i.e., position 1) individual. Diff Income $e^{7}$ is similarly defined for the richest individual. 
Figure 1: Standard representation of the choice question in the experiment

Between the two societies below, which one would you prefer to live in? The red bar in each graph indicates your position in that society.
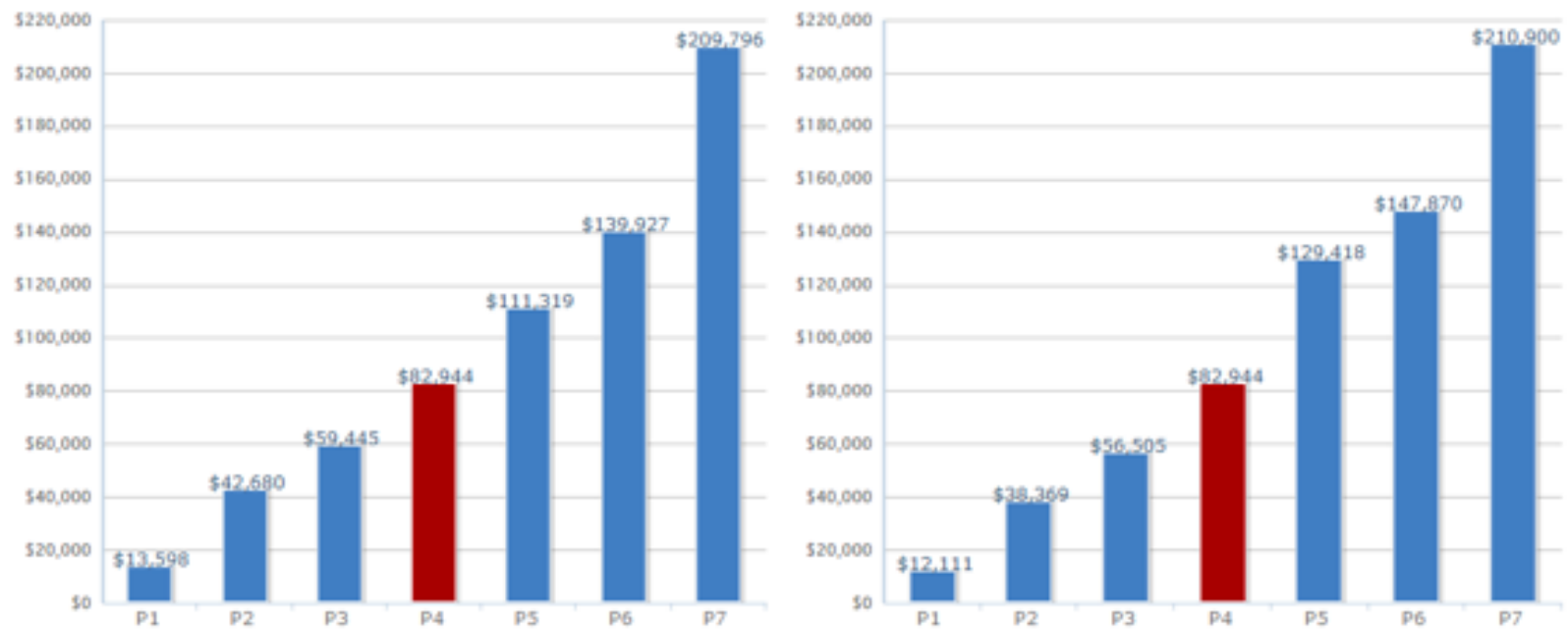

Society A

$\mathrm{O}$

Society B
O 
Figure 2: Alternative graphical representation of choice question

Between the tao sociebes below, which one would you prefer to live in? The red bar in each graph indicates your position in that scciely.
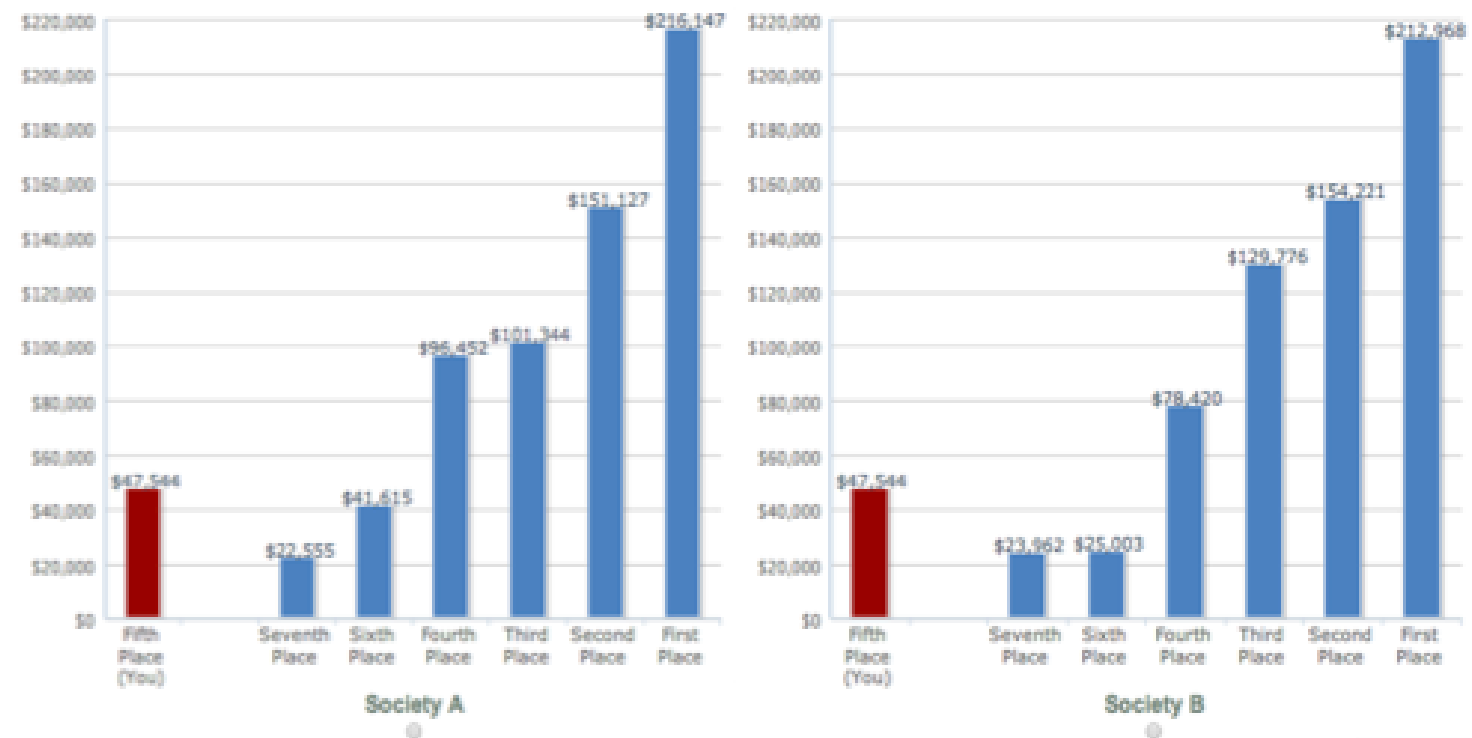

Next :

I 
Figure 3: Effect of higher income in position $q$ on subject's propensity to choose distribution $B$ over $A$

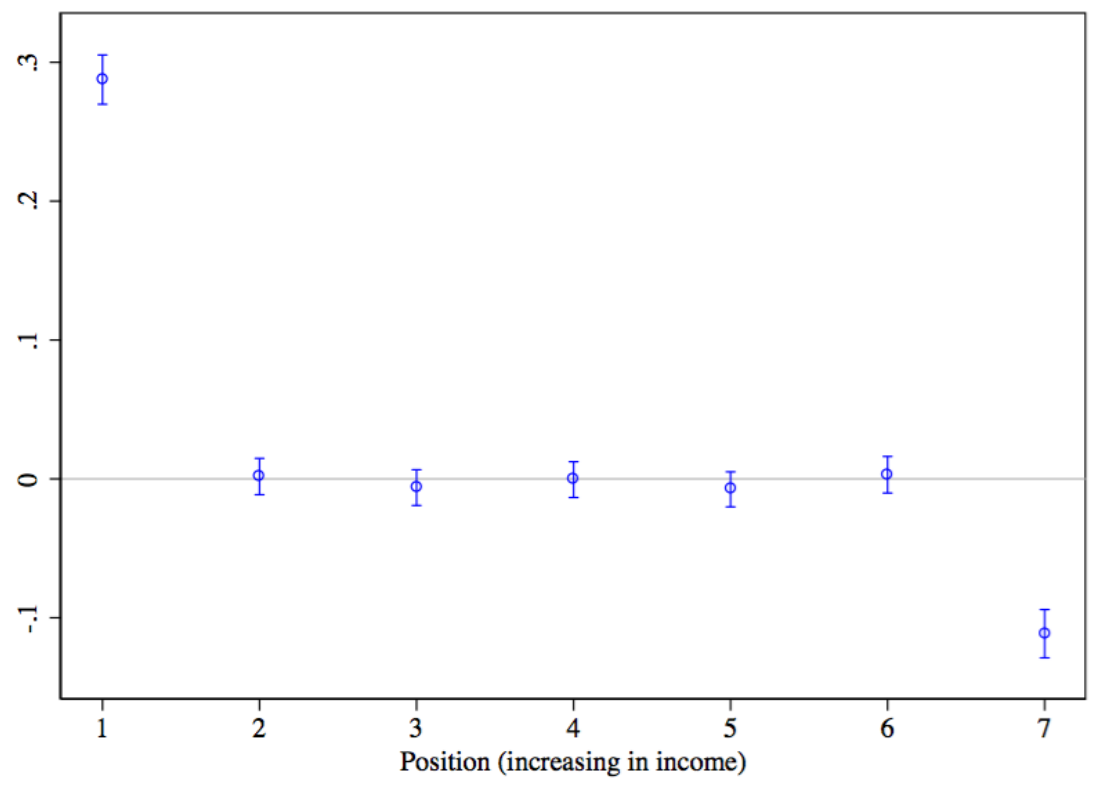

Note: The coefficients plotted for each graph are generated by regressing Choose $_{i k}^{B}=\alpha+$ $\sum_{q=1}^{7} \lambda_{q}$ SignIncome $_{q, i k}+P_{i k}+\epsilon_{i k}$, where $i$ indexes the subject and $k$ a particular iteration of the experiment (i.e., equation (4) in the text). The 95-percent confidence intervals plotted are based on standard errors clustered by subject. 
Figure 4: Effect of higher income in position $q$ on subject's propensity to choose distribution $B$ over $A$, separately by position $p$ of subject herself
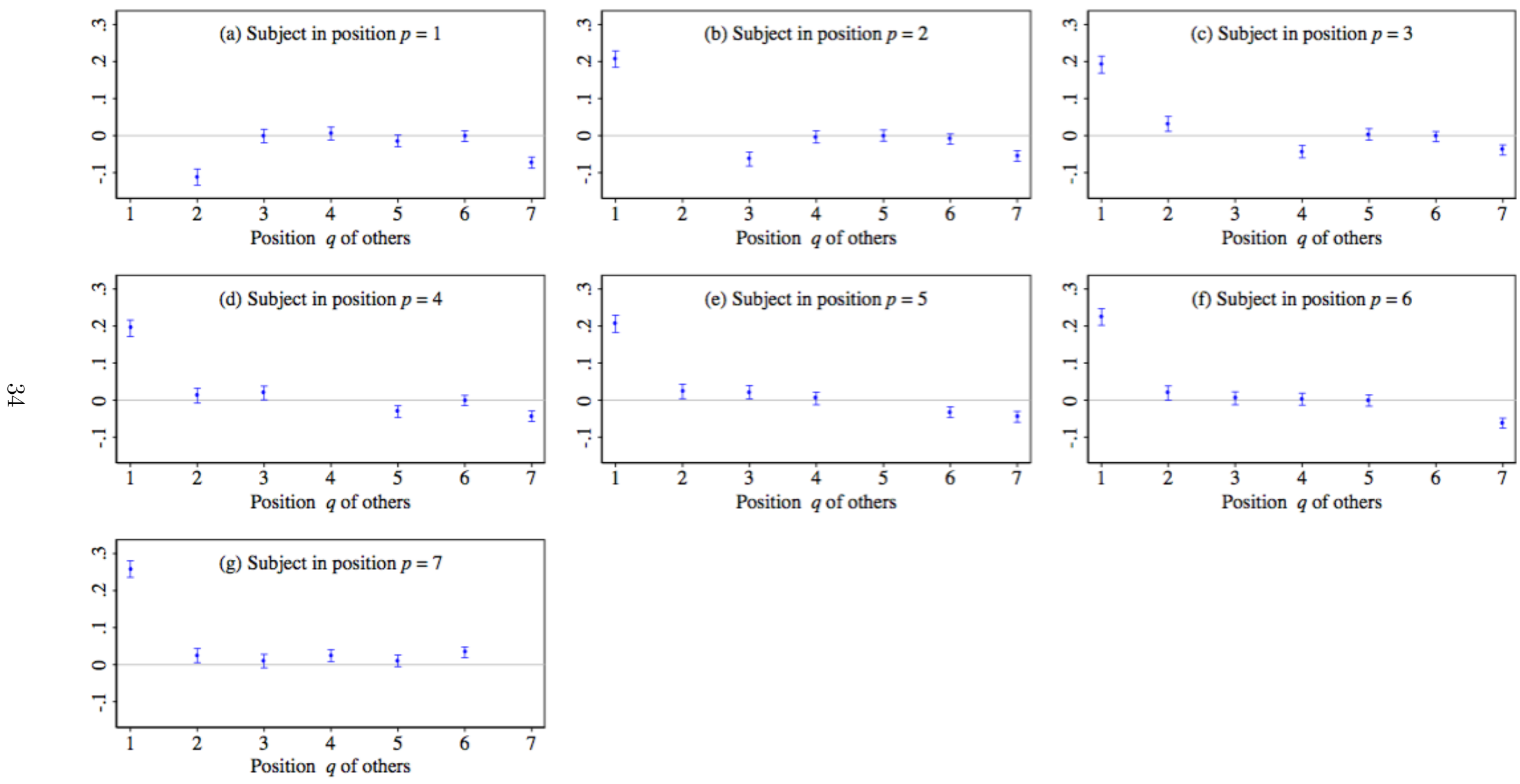

Note: The coefficients plotted for each graph are generated by regressing (for each position $p$ ) Choice ${ }_{i k}^{B}=\alpha+\sum_{q \neq p} \eta_{q}^{p} S_{i g n I n c o m e}, i k+\epsilon_{i k}$ where $i$ indexes the subject and $k$ a particular iteration of the experiment (i.e., equation (5) in the text). The 95-percent confidence intervals plotted are based on standard errors clustered by subject. 
Table A1: Survey Sessions Details

\begin{tabular}{llcc}
\hline Session & \multicolumn{1}{c}{ Date } & Survey Obs & Analysis Obs \\
\hline Percentage Differences & September 09, 2013 & 1025 & 1025 \\
Absolute Differences & September 17, 2013 & 1503 & 1503 \\
Own Income Variation & November 14, 2013 & 1003 & 808 \\
Nine Person & November 15, 2013 & 1002 & 773 \\
Alternative Formatting & November 27, 2013 & 1000 & 663 \\
High Inequality & December 27, 2013 & 1001 & 639 \\
Very High Inequality & December 30, 2013 & 1005 & 725 \\
Real Stakes & August 7, 2014 & 967 & 746 \\
\hline
\end{tabular}

Notes: Total survey observations and analysis observations differ because we drop all participants who had taken a previous survey from our analysis. 
Table A2: Bottom, Topmost and Local Inequality Aversion in the Main Sample, Reweighted

\begin{tabular}{lcccc}
\hline & \multicolumn{3}{c}{ Dep. var: Chose Second Distribution } \\
\cline { 2 - 5 } & $(1)$ & $(2)$ & $(3)$ & $(4)$ \\
\hline Diff Income $^{+1}$ in B vs. A & $-0.0371^{* * *}$ & $-0.0372^{* * *}$ & $-0.0372^{* * *}$ & $-0.0388^{* * *}$ \\
& {$[0.00415]$} & {$[0.00416]$} & {$[0.00416]$} & {$[0.00438]$} \\
Diff Income $^{+2}$ in B vs. A & -0.000224 & -0.000329 & -0.000328 & -0.000106 \\
& {$[0.00365]$} & {$[0.00365]$} & {$[0.00365]$} & {$[0.00382]$} \\
Diff Income $^{1}$ in B vs. A & $0.195^{* * *}$ & $0.196^{* * *}$ & $0.196^{* * *}$ & $0.200^{* * *}$ \\
& {$[0.00662]$} & {$[0.00662]$} & {$[0.00662]$} & {$[0.00690]$} \\
Diff Income & \\
& $-0.0426^{* * *}$ & $-0.0425^{* * *}$ & $-0.0425^{* * *}$ & $-0.0442^{* * *}$ \\
& {$[0.00407]$} & {$[0.00407]$} & {$[0.00407]$} & {$[0.00431]$} \\
\hline Above Two/One Diff. & $.03691^{* * *}$ & $.03691^{* * *}$ & $.03684^{* * *}$ & $.03866^{* * *}$ \\
Question-Order FE & No & Yes & Yes & Yes \\
Position & No & No & Yes & Yes \\
Ex. short duration & No & No & No & Yes \\
Observations & 14515 & 14515 & 14515 & 13229 \\
R2 & 0.103 & 0.103 & 0.104 & 0.109 \\
\hline
\end{tabular}

Notes: All regressions use robust standard errors clustered at the subject level. All observations are reweighted to be reflective of the GSS population based on age (above 30), gender, income (above $\$ 60,000$ ), and belief that the government should reduce income differences. Only subjects who completed all 10 iterations are included ${ }^{*} p<0.1,{ }^{* *} p<0.05,{ }^{* * *} p<0.01$. In all specifications, monetary values are expressed in units of $\$ 10,000$ to make the table more readable.

Diff Income $e^{+1}$ is the difference in income between Societies B and A for the individual in the position directly above the subject's own. Diff Income ${ }^{+2}$ is similarly defined for the individual two positions above the subject. Diff Income ${ }^{7}$ is the difference in income between Societies B and A for the richest (i.e., position 7) individual. Diff Income ${ }^{1}$ is similarly defined for the poorest individual. 
Table A3: Bottom, Topmost and Local Inequality Aversion in the Main Sample, including retakers

\begin{tabular}{lcccc}
\hline & \multicolumn{3}{c}{ Dep. var: Chose Second Distribution } \\
\cline { 2 - 5 } & $(1)$ & $(2)$ & $(3)$ & $(4)$ \\
\hline Diff Income $^{+1}$ in B vs. A & $-0.0371^{* * *}$ & $-0.0372^{* * *}$ & $-0.0372^{* * *}$ & $-0.0388^{* * *}$ \\
& {$[0.00415]$} & {$[0.00416]$} & {$[0.00416]$} & {$[0.00438]$} \\
Diff Income $^{+2}$ in B vs. A & -0.000224 & -0.000329 & -0.000328 & -0.000106 \\
& {$[0.00365]$} & {$[0.00365]$} & {$[0.00365]$} & {$[0.00382]$} \\
Diff Income $^{1}$ in B vs. A & $0.195^{* * *}$ & $0.196^{* * *}$ & $0.196^{* * *}$ & $0.200^{* * *}$ \\
& {$[0.00662]$} & {$[0.00662]$} & {$[0.00662]$} & {$[0.00690]$} \\
Diff Income $^{7}$ in B vs. A & $-0.0426^{* * *}$ & $-0.0425^{* * *}$ & $-0.0425^{* * *}$ & $-0.0442^{* * *}$ \\
& {$[0.00407]$} & {$[0.00407]$} & {$[0.00407]$} & {$[0.00431]$} \\
\hline Above Two/One Diff. $_{\text {Question-Order FE }}$ & $.03691^{* * *}$ & $.03691^{* * *}$ & $.03684^{* * *}$ & $.03866^{* * *}$ \\
Position & No & Yes & Yes & Yes \\
Ex. short duration & No & No & Yes & Yes \\
Observations & No & No & No & Yes \\
R2 & 14515 & 14515 & 14515 & 13229 \\
Dotes Alt & 0.103 & 0.103 & 0.104 & 0.109 \\
\hline
\end{tabular}

Notes: All regressions use robust standard errors clustered at the subject level. The sample in this table includes participants in the "Absolute Differences" and "Percentage Differences" experiments run in September 2013 (see text for details). Only subjects who completed all 10 iterations are included ${ }^{*} p<0.1,{ }^{* *} p<0.05,{ }^{* * *} p<0.01$. Subjects who completed multiple versions of the survey are now included. In all specifications, monetary values are expressed in units of $\$ 10,000$ to make the table more readable. Diff Income $e^{+1}$ is the difference in income between Societies B and A for the individual in the position directly above the subject's own. Diff Income $e^{+2}$ is similarly defined for the individual two positions above the subject.

Diff Income $e^{7}$ is the difference in income between Societies B and A for the richest (i.e., position 7) individual. Diff Income ${ }^{1}$ is similarly defined for the poorest individual. 
Table A4: Bottom, Topmost and Local Inequality Aversion in the Main Sample, controlling for Surplus

\begin{tabular}{lcccc}
\hline & \multicolumn{3}{c}{ Dep. var: Chose Distribution B over A } \\
\cline { 2 - 5 } & $(1)$ & $(2)$ & $(3)$ & $(4)$ \\
\hline Diff Income $^{+1}$ in B vs. A & $-0.0438^{* * *}$ & $-0.0439^{* * *}$ & $-0.0439^{* * *}$ & $-0.0444^{* * *}$ \\
& {$[0.00495]$} & {$[0.00495]$} & {$[0.00495]$} & {$[0.00521]$} \\
Diff Income $^{+2}$ in B vs. A & -0.00509 & -0.00521 & -0.00519 & -0.00418 \\
& {$[0.00405]$} & {$[0.00405]$} & {$[0.00405]$} & {$[0.00423]$} \\
Diff Income 1 in B vs. A & $0.189^{* * *}$ & $0.189^{* * *}$ & $0.189^{* * *}$ & $0.195^{* * *}$ \\
& {$[0.00705]$} & {$[0.00705]$} & {$[0.00705]$} & {$[0.00732]$} \\
Diff Income ${ }^{7}$ in B vs. A & $-0.0480^{* * *}$ & $-0.0480^{* * *}$ & $-0.0479^{* * *}$ & $-0.0487^{* * *}$ \\
& {$[0.00463]$} & {$[0.00463]$} & {$[0.00463]$} & {$[0.00490]$} \\
DiffS Surplus in B vs. A & $0.00668^{* *}$ & $0.00670^{* *}$ & $0.00669^{* *}$ & $0.00563^{* *}$ \\
& {$[0.00261]$} & {$[0.00261]$} & {$[0.00261]$} & {$[0.00273]$} \\
\hline Above Two/One Diff. & $.03873^{* * *}$ & $.03873^{* * *}$ & $.03866^{* * *}$ & $.0402^{* * *}$ \\
Question-Order FE & No & Yes & Yes & Yes \\
Position & No & No & Yes & Yes \\
Ex. short duration & No & No & No & Yes \\
Observations & 14515 & 14515 & 14515 & 13229 \\
R2 & 0.103 & 0.104 & 0.104 & 0.109 \\
\hline
\end{tabular}

Notes: All regressions include robust standard errors clustered at the subject level. The sample in this table includes participants in the "Absolute Differences" and "Percentage Differences" experiments run in September 2013 (see text for details). Only subjects who completed all 10 iterations are included ${ }^{*} p<0.1,{ }^{* *} p<0.05,{ }^{* * *} p<0.01$. In all specifications, monetary values are expressed in units of $\$ 10,000$ to make the table more readable. Diff Income ${ }^{+1}$ is the difference in income between Societies B and A for the individual in the position directly above the subject's own. Diff Income ${ }^{+2}$ is similarly defined for the individual two positions above the subject.

Diff Income $e^{7}$ is the difference in income between Societies B and A for the richest (i.e., position 7) individual. Diff Income ${ }^{1}$ is similarly defined for the poorest individual. DiffSurplus is the difference in the sum of incomes between Societies B and A. See the text for additional details on variable definitions. 
Table A5: Bottom, Topmost and Local Inequality Aversion in the Main Sample, controlling for Gini Coefficient

\begin{tabular}{lcccc}
\hline & \multicolumn{3}{c}{ Dep. var: Chose Distribution B over A } \\
\cline { 2 - 5 } & $(1)$ & $(2)$ & $(3)$ & $(4)$ \\
\hline Diff Income $^{+1}$ in B vs. A & $-0.0391^{* * *}$ & $-0.0393^{* * *}$ & $-0.0392^{* * *}$ & $-0.0409^{* * *}$ \\
& {$[0.00418]$} & {$[0.00418]$} & {$[0.00418]$} & {$[0.00441]$} \\
Diff Income ${ }^{+2}$ in B vs. A & -0.000331 & -0.000436 & -0.000435 & -0.000261 \\
& {$[0.00364]$} & {$[0.00364]$} & {$[0.00365]$} & {$[0.00381]$} \\
Diff Income ${ }^{1}$ in B vs. A & $0.175^{* * *}$ & $0.175^{* * *}$ & $0.175^{* * *}$ & $0.179^{* * *}$ \\
& {$[0.00843]$} & {$[0.00842]$} & {$[0.00842]$} & {$[0.00873]$} \\
Diff Income ${ }^{7}$ in B vs. A & $-0.0341^{* * *}$ & $-0.0341^{* * *}$ & $-0.0340^{* * *}$ & $-0.0355^{* * *}$ \\
& {$[0.00467]$} & {$[0.00467]$} & {$[0.00467]$} & {$[0.00492]$} \\
DiffGini in B vs. A & $-10349.8^{* * *}$ & $-10372.6^{* * *}$ & $-10393.1^{* * *}$ & $-10596.9^{* * *}$ \\
& {$[2761.9]$} & {$[2761.7]$} & {$[2762.3]$} & {$[2881.1]$} \\
\hline Above Two/One Diff. & $.03882^{* * *}$ & $.03882^{* * *}$ & $.03876^{* * *}$ & $.04063^{* * *}$ \\
Question-Order FE & No & Yes & Yes & Yes \\
Position & No & No & Yes & Yes \\
Ex. short duration & No & No & No & Yes \\
Observations & 14515 & 14515 & 14515 & 13229 \\
R2 & 0.104 & 0.104 & 0.105 & 0.110 \\
\hline Notes: All reg & & &
\end{tabular}

Notes: All regressions include robust standard errors clustered at the subject level. The sample in this table includes participants in the "Absolute Differences" and "Percentage Differences" experiments run in September 2013 (see text for details). Only subjects who completed all 10 iterations are included ${ }^{*} p<0.1,{ }^{* *} p<0.05,{ }^{* * *} p<0.01$. In all specifications, monetary values are expressed in units of $\$ 10,000$ to make the table more readable. Diff Income ${ }^{+1}$ is the difference in income between Societies B and A for the individual in the position directly above the subject's own. Diff Income $e^{+2}$ is similarly defined for the individual two positions above the subject. Diff Income $e^{7}$ is the difference in income between Societies B and A for the richest (i.e., position 7) individual. Diff Income $e^{1}$ is similarly defined for the poorest individual. DiffGini is the difference in the Gini Coefficient between Societies B and A. See the text for additional details on variable definitions. 
Table A6: Bottom, Topmost and Local Inequality Aversion in the Absolute Differences Sample

\begin{tabular}{lccccc}
\hline & \multicolumn{5}{c}{ Dep. var: Chose Distribution B over A } \\
\cline { 2 - 6 } & $(1)$ & $(2)$ & $(3)$ & $(4)$ & $(5)$ \\
\hline Diff Income $^{+1}$ in B vs. A & $-0.0544^{* * *}$ & $-0.0631^{* * *}$ & $-0.0630^{* * *}$ & $-0.0630^{* * *}$ & $-0.0611^{* * *}$ \\
& {$[0.00700]$} & {$[0.00807]$} & {$[0.00805]$} & {$[0.00805]$} & {$[0.00832]$} \\
Diff Income $^{+2}$ in B vs. A & 0.000331 & -0.00666 & -0.00673 & -0.00672 & -0.00714 \\
& {$[0.00640]$} & {$[0.00709]$} & {$[0.00708]$} & {$[0.00708]$} & {$[0.00726]$} \\
Diff Income 1 in B vs. A & $0.206^{* * *}$ & $0.197^{* * *}$ & $0.198^{* * *}$ & $0.198^{* * *}$ & $0.202^{* * *}$ \\
& {$[0.00775]$} & {$[0.00878]$} & {$[0.00877]$} & {$[0.00877]$} & {$[0.00906]$} \\
DiffIncome ${ }^{7}$ in B vs. A & $-0.0620^{* * *}$ & $-0.0687^{* * *}$ & $-0.0688^{* * *}$ & $-0.0688^{* * *}$ & $-0.0711^{* * *}$ \\
& {$[0.00779]$} & {$[0.00850]$} & {$[0.00850]$} & {$[0.00850]$} & {$[0.00880]$} \\
DiffSurplus in B vs. A & & $0.00873^{* *}$ & $0.00868^{* *}$ & $0.00869^{* *}$ & $0.00775^{*}$ \\
& & {$[0.00419]$} & {$[0.00418]$} & {$[0.00418]$} & {$[0.00432]$} \\
\hline Above Two/One Diff. & $.05469^{* * *}$ & $.05643^{* * *}$ & $.05625^{* * *}$ & $.05626^{* * *}$ & $.05394^{* * *}$ \\
Round FE & No & No & Yes & Yes & Yes \\
Position & No & No & No & Yes & Yes \\
Ex. short duration & No & No & No & No & Yes \\
Observations & 8669 & 8669 & 8669 & 8669 & 8139 \\
R2 & 0.133 & 0.133 & 0.135 & 0.135 & 0.139 \\
\hline Nots: All &
\end{tabular}

Notes: All regressions use robust standard errors clustered at the subject level. Only subjects who completed all 10 iterations are included ${ }^{*} p<0.1,{ }^{* *} p<0.05,{ }^{* * *} p<0.01$. In all specifications, monetary values are expressed in units of $\$ 10,000$ to make the table more readable.

Dif Income $^{+1}$ is the difference in income between Societies B and A for the individual in the position directly above the subject's own. Diff Income ${ }^{+2}$ is similarly defined for the individual two positions above the subject. Diff Income ${ }^{7}$ is the difference in income between Societies B and $\mathrm{A}$ for the richest (i.e., position 7) individual. Diff Income ${ }^{1}$ is similarly defined for the poorest individual. 
Table A7: Bottom, Topmost and Local Inequality Aversion in the Percentage Differences Sample

\begin{tabular}{lcccc}
\hline & \multicolumn{4}{c}{ Dep. var: Chose Distribution B over A } \\
\cline { 2 - 5 } & $(1)$ & $(2)$ & $(3)$ & $(4)$ \\
\hline Diff Income $^{+1}$ in B vs. A & $-0.0280^{* * *}$ & $-0.0281^{* * *}$ & $-0.0281^{* * *}$ & $-0.0305^{* * *}$ \\
& {$[0.00514]$} & {$[0.00515]$} & {$[0.00515]$} & {$[0.00549]$} \\
Diff Income $^{+2}$ in B vs. A & -0.000459 & -0.000588 & -0.000538 & 0.000398 \\
& {$[0.00443]$} & {$[0.00443]$} & {$[0.00444]$} & {$[0.00469]$} \\
Diff Income $^{1}$ in B vs. A & $0.166^{* * *}$ & $0.166^{* * *}$ & $0.166^{* * *}$ & $0.172^{* * *}$ \\
& {$[0.0128]$} & {$[0.0129]$} & {$[0.0129]$} & {$[0.0135]$} \\
Diff Income $^{7}$ in B vs. A & $-0.0365^{* * *}$ & $-0.0364^{* * *}$ & $-0.0363^{* * *}$ & $-0.0371^{* * *}$ \\
& {$[0.00474]$} & {$[0.00474]$} & {$[0.00474]$} & {$[0.00507]$} \\
\hline Above Two/One Diff. & $.0275^{* * *}$ & $.02756^{* * *}$ & $.02754^{* * *}$ & $.03093^{* * *}$ \\
Question-Order FE & No & Yes & Yes & Yes \\
Position & No & No & Yes & Yes \\
Ex. short duration & No & No & No & Yes \\
Observations & 5846 & 5846 & 5846 & 5090 \\
R2 & 0.0640 & 0.0650 & 0.0657 & 0.0696 \\
\hline
\end{tabular}

Notes: All regressions use robust standard errors clustered at the subject level. Only subjects who completed all 10 iterations are included ${ }^{*} p<0.1,{ }^{* *} p<0.05,{ }^{* * *} p<0.01$. In all specifications, monetary values are expressed in units of $\$ 10,000$ to make the table more readable.

Diff Income $e^{+1}$ is the difference in income between Societies B and A for the individual in the position directly above the subject's own. Diff Income ${ }^{+2}$ is similarly defined for the individual two positions above the subject. Diff Income ${ }^{7}$ is the difference in income between Societies B and $\mathrm{A}$ for the richest (i.e., position 7) individual. Dif f Income ${ }^{1}$ is similarly defined for the poorest individual. 
Table A8: Bottom, Topmost and Local Inequality Aversion in the Own Income Variation Sample

\begin{tabular}{lcccc}
\hline & \multicolumn{3}{c}{ Dep. var: Chose Distribution B over A } \\
\cline { 2 - 5 } & $(1)$ & $(2)$ & $(3)$ & $(4)$ \\
\hline Diff Income $^{+1}$ in B vs. A & $-0.0126^{* * *}$ & $-0.0125^{* * *}$ & $-0.0122^{* *}$ & $-0.0105^{* *}$ \\
& {$[0.00476]$} & {$[0.00475]$} & {$[0.00475]$} & {$[0.00486]$} \\
Diff Income $^{+2}$ in B vs. A & -0.000666 & -0.000624 & -0.000735 & -0.000170 \\
& {$[0.00451]$} & {$[0.00450]$} & {$[0.00450]$} & {$[0.00456]$} \\
Diff Income $^{1}$ in B vs. A & $0.135^{* * *}$ & $0.135^{* * *}$ & $0.135^{* * *}$ & $0.136^{* * *}$ \\
& {$[0.0125]$} & {$[0.0125]$} & {$[0.0125]$} & {$[0.0127]$} \\
Diff Income $^{7}$ in B vs. A & $-0.0400^{* * *}$ & $-0.0403^{* * *}$ & $-0.0402^{* * *}$ & $-0.0405^{* * *}$ \\
& {$[0.00401]$} & {$[0.00403]$} & {$[0.00403]$} & {$[0.00412]$} \\
Diff Income $^{\text {OWN } \text { in B vs. A }}$ & $0.211^{* * *}$ & $0.211^{* * *}$ & $0.211^{* * *}$ & $0.210^{* * *}$ \\
& {$[0.00657]$} & {$[0.00657]$} & {$[0.00658]$} & {$[0.00668]$} \\
\hline Above Two/One Diff. & $.01193^{*}$ & $.01183^{*}$ & $.01149^{*}$ & .01029 \\
Question-Order FE & No & Yes & Yes & Yes \\
Position & No & No & Yes & Yes \\
Ex. short duration & No & No & No & Yes \\
Observations & 4573 & 4573 & 4573 & 4397 \\
R2 & 0.288 & 0.289 & 0.290 & 0.289 \\
\hline
\end{tabular}

Notes: All regressions use robust standard errors clustered at the subject level. Only subjects who completed all 10 iterations are included ${ }^{*} p<0.1,{ }^{* *} p<0.05,{ }^{* * *} p<0.01$. In all specifications, monetary values are expressed in units of $\$ 10,000$ to make the table more readable.

Dif f Income ${ }^{+1}$ is the difference in income between Societies B and A for the individual in the position directly above the subject's own. Diff Income ${ }^{+2}$ is similarly defined for the individual two positions above the subject. Diff Income $e^{7}$ is the difference in income between Societies B and A for the richest (i.e., position 7) individual. Diff Income ${ }^{1}$ is similarly defined for the poorest individual. Diff Income $e^{O W N}$ is the difference in income between Societies B and A for the subject own income. 
Table A9: Bottom, Topmost and Local Inequality Aversion in the High Inequality Sample

\begin{tabular}{lcccc}
\hline & \multicolumn{4}{c}{ Dep. var: Chose Distribution B over A } \\
\cline { 2 - 5 } & $(1)$ & $(2)$ & $(3)$ & $(4)$ \\
\hline Diff Income $^{+1}$ in B vs. A & $-0.0260^{* * *}$ & $-0.0259^{* * *}$ & $-0.0259^{* * *}$ & $-0.0272^{* * *}$ \\
& {$[0.00541]$} & {$[0.00541]$} & {$[0.00541]$} & {$[0.00552]$} \\
Diff Income $^{+2}$ in B vs. A & -0.00491 & -0.00469 & -0.00476 & -0.00462 \\
& {$[0.00394]$} & {$[0.00396]$} & {$[0.00396]$} & {$[0.00401]$} \\
& $0.324^{* * *}$ & $0.322^{* * *}$ & $0.321^{* * *}$ & $0.324^{* * *}$ \\
Diff Income $^{1}$ in B vs. A & {$[0.0405]$} & {$[0.0405]$} & {$[0.0406]$} & {$[0.0413]$} \\
& $-0.0568^{* * *}$ & $-0.0569^{* * *}$ & $-0.0569^{* * *}$ & $-0.0574^{* * *}$ \\
Diff Income $^{7}$ in B vs. A & {$[0.00384]$} & {$[0.00385]$} & {$[0.00385]$} & {$[0.00396]$} \\
& $.02111^{* * *}$ & $.02117^{* * *}$ & $.0211^{* * *}$ & $.0226^{* * *}$ \\
Above Two/One Diff. & No & Yes & Yes & Yes \\
Question-Order FE & No & No & Yes & Yes \\
Position & No & No & No & Yes \\
Ex. short duration & 3631 & 3631 & 3631 & 3482 \\
Observations & 0.128 & 0.130 & 0.131 & 0.133 \\
R2 &
\end{tabular}

Notes: All regressions use robust standard errors clustered at the subject level. Only subjects who completed all 10 iterations are included ${ }^{*} p<0.1,{ }^{* *} p<0.05,{ }^{* * *} p<0.01$. In all specifications, monetary values are expressed in units of $\$ 10,000$ to make the table more readable.

Diff Income $e^{+1}$ is the difference in income between Societies B and A for the individual in the position directly above the subject's own. Diff Income ${ }^{+2}$ is similarly defined for the individual two positions above the subject. Diff Income $e^{7}$ is the difference in income between Societies B and A for the richest (i.e., position 7) individual. Dif Income $^{1}$ is similarly defined for the poorest individual. 
Table A10: Bottom, Topmost and Local Inequality Aversion in the Very High Inequality Sample

\begin{tabular}{lcccc}
\hline & \multicolumn{4}{c}{ Dep. var: Chose Distribution B over A } \\
\cline { 2 - 5 } & $(1)$ & $(2)$ & $(3)$ & $(4)$ \\
\hline Diff Income $^{+1}$ in B vs. A & $-0.0265^{* * *}$ & $-0.0265^{* * *}$ & $-0.0264^{* * *}$ & $-0.0267^{* * *}$ \\
& {$[0.00327]$} & {$[0.00326]$} & {$[0.00326]$} & {$[0.00328]$} \\
Diff Income $^{+2}$ in B vs. A & -0.000830 & -0.000773 & -0.000806 & -0.000378 \\
& {$[0.00277]$} & {$[0.00276]$} & {$[0.00276]$} & {$[0.00279]$} \\
Diff Income $^{1}$ in B vs. A & $0.311^{* * *}$ & $0.309^{* * *}$ & $0.309^{* * *}$ & $0.317^{* * *}$ \\
& {$[0.0407]$} & {$[0.0409]$} & {$[0.0409]$} & {$[0.0410]$} \\
Diff Income $^{7}$ in B vs. A & $-0.0325^{* * *}$ & $-0.0325^{* * *}$ & $-0.0325^{* * *}$ & $-0.0324^{* * *}$ \\
& {$[0.00250]$} & {$[0.00250]$} & {$[0.00250]$} & {$[0.00252]$} \\
\hline Above Two/One Diff. & $.0257^{* * *}$ & $.0257^{* * *}$ & $.02562^{* * *}$ & $.02633^{* * *}$ \\
Question-Order FE & No & Yes & Yes & Yes \\
Position & No & No & Yes & Yes \\
Ex. short duration & No & No & No & Yes \\
Observations & 4109 & 4109 & 4109 & 4042 \\
R2 & 0.0992 & 0.100 & 0.101 & 0.101 \\
\hline
\end{tabular}

Notes: All regressions use robust standard errors clustered at the subject level. Only subjects who completed all 10 iterations are included ${ }^{*} p<0.1,{ }^{* *} p<0.05,{ }^{* * *} p<0.01$. In all specifications, monetary values are expressed in units of $\$ 10,000$ to make the table more readable.

Diff Income $e^{+1}$ is the difference in income between Societies B and A for the individual in the position directly above the subject's own. Diff Income ${ }^{+2}$ is similarly defined for the individual two positions above the subject. Diff Income ${ }^{7}$ is the difference in income between Societies B and $\mathrm{A}$ for the richest (i.e., position 7) individual. Dif f Income ${ }^{1}$ is similarly defined for the poorest individual. 
Table A11: Bottom, Topmost and Local Inequality Aversion in the Nine Person Sample

\begin{tabular}{lcccc}
\hline & \multicolumn{4}{c}{ Dep. var: Chose Distribution B over A } \\
\cline { 2 - 5 } & $(1)$ & $(2)$ & $(3)$ & $(4)$ \\
\hline Diff Income $^{+1}$ in B vs. A & $-0.0545^{* * *}$ & $-0.0543^{* * *}$ & $-0.0545^{* * *}$ & $-0.0556^{* * *}$ \\
& {$[0.00870]$} & {$[0.00871]$} & {$[0.00873]$} & {$[0.00874]$} \\
Diff Income $^{+2}$ in B vs. A & -0.00225 & -0.00234 & -0.00224 & -0.00286 \\
& {$[0.00728]$} & {$[0.00729]$} & {$[0.00731]$} & {$[0.00741]$} \\
& $0.245^{* * *}$ & $0.245^{* * *}$ & $0.245^{* * *}$ & $0.241^{* * *}$ \\
Diff Income $^{1}$ in B vs. A & {$[0.0232]$} & {$[0.0233]$} & {$[0.0233]$} & {$[0.0235]$} \\
& $-0.0505^{* * *}$ & $-0.0505^{* * *}$ & $-0.0505^{* * *}$ & $-0.0509^{* * *}$ \\
Diff Income $^{9}$ in B vs. A & {$[0.00593]$} & {$[0.00593]$} & {$[0.00593]$} & {$[0.00597]$} \\
& $.05229^{* * *}$ & $.05198^{* * *}$ & $.05223^{* * *}$ & $.05273^{* * *}$ \\
Above Two/One Diff. & No & Yes & Yes & Yes \\
Question-Order FE & No & No & Yes & Yes \\
Position & No & No & No & Yes \\
Ex. short duration & 3396 & 3396 & 3396 & 3330 \\
Observations & 0.0827 & 0.0834 & 0.0836 & 0.0834 \\
R2 & &
\end{tabular}

Notes: All regressions use robust standard errors clustered at the subject level. Only subjects who completed all 10 iterations are included ${ }^{*} p<0.1,{ }^{* *} p<0.05,{ }^{* * *} p<0.01$. In all specifications, monetary values are expressed in units of $\$ 10,000$ to make the table more readable.

Diff Income ${ }^{+1}$ is the difference in income between Societies B and A for the individual in the position directly above the subject's own. Diff Income $e^{+2}$ is similarly defined for the individual two positions above the subject. Diff Income ${ }^{9}$ is the difference in income between Societies B and A for the richest (i.e., position 9) individual. Diff Income ${ }^{1}$ is similarly defined for the poorest individual. 
Table A12: Bottom, Topmost and Local Inequality Aversion in the Alternative Formatting Sample

\begin{tabular}{lcccc}
\hline & \multicolumn{4}{c}{ Dep. var: Chose Distribution B over A } \\
\cline { 2 - 5 } & $(1)$ & $(2)$ & $(3)$ & $(4)$ \\
\hline Diff Income $^{+1}$ in B vs. A & $-0.0408^{* * *}$ & $-0.0407^{* * *}$ & $-0.0407^{* * *}$ & $-0.0411^{* * *}$ \\
& {$[0.00641]$} & {$[0.00640]$} & {$[0.00639]$} & {$[0.00666]$} \\
Diff Income $^{+2}$ in B vs. A & -0.00220 & -0.00221 & -0.00226 & -0.00227 \\
& {$[0.00513]$} & {$[0.00514]$} & {$[0.00514]$} & {$[0.00534]$} \\
& $0.178^{* * *}$ & $0.176^{* * *}$ & $0.176^{* * *}$ & $0.183^{* * *}$ \\
Diff Income $^{1}$ in B vs. A & {$[0.0152]$} & {$[0.0153]$} & {$[0.0152]$} & {$[0.0159]$} \\
& $-0.0547^{* * *}$ & $-0.0545^{* * *}$ & $-0.0547^{* * *}$ & $-0.0522^{* * *}$ \\
Diff Income $^{7}$ in B vs. A & {$[0.00567]$} & {$[0.00568]$} & {$[0.00568]$} & {$[0.00592]$} \\
& $.03859^{* * *}$ & $.03852^{* * *}$ & $.03849^{* * *}$ & $.03879^{* * *}$ \\
Above Two/One Diff. $_{\text {Question-Order FE }}$ & No & Yes & Yes & Yes \\
Position & No & No & Yes & Yes \\
Ex. short duration & No & No & No & Yes \\
Observations & 3729 & 3729 & 3729 & 3417 \\
R2 & 0.101 & 0.104 & 0.104 & 0.105 \\
\hline
\end{tabular}

Notes: All regressions use robust standard errors clustered at the subject level. Only subjects who completed all 10 iterations are included ${ }^{*} p<0.1,{ }^{* *} p<0.05,{ }^{* * *} p<0.01$. In all specifications, monetary values are expressed in units of $\$ 10,000$ to make the table more readable.

Diff Income $e^{+1}$ is the difference in income between Societies B and A for the individual in the position directly above the subject's own. Diff Income ${ }^{+2}$ is similarly defined for the individual two positions above the subject. Diff Income ${ }^{7}$ is the difference in income between Societies B and $\mathrm{A}$ for the richest (i.e., position 7) individual. Dif f Income ${ }^{1}$ is similarly defined for the poorest individual. 
Table A13: Bottom, Topmost and Local Inequality Aversion in the Real Stakes Sample

\begin{tabular}{lcccc}
\hline & \multicolumn{4}{c}{ Dep. var: Chose Distribution B over A } \\
\cline { 2 - 5 } & $(1)$ & $(2)$ & $(3)$ & $(4)$ \\
\hline Diff Income $^{+1}$ in B vs. A & -0.00509 & -0.00496 & -0.00520 & -0.00566 \\
& {$[0.00574]$} & {$[0.00571]$} & {$[0.00571]$} & {$[0.00598]$} \\
Diff Income $^{+2}$ in B vs. A & -0.000258 & 0.000159 & 0.000204 & 0.00113 \\
& {$[0.00480]$} & {$[0.00484]$} & {$[0.00484]$} & {$[0.00512]$} \\
& $0.223^{* * *}$ & $0.223^{* * *}$ & $0.223^{* * *}$ & $0.225^{* * *}$ \\
Diff Income $^{1}$ in B vs. A & {$[0.0137]$} & {$[0.0137]$} & {$[0.0137]$} & {$[0.0143]$} \\
& $-0.0402^{* * *}$ & $-0.0403^{* * *}$ & $-0.0402^{* * *}$ & $-0.0432^{* * *}$ \\
Diff Income $^{7}$ in B vs. A & {$[0.00507]$} & {$[0.00505]$} & {$[0.00504]$} & {$[0.00516]$} \\
& .00483 & .00512 & .00541 & .00679 \\
Above Two/One Diff. $_{\text {Question-Order FE }}$ & No & Yes & Yes & Yes \\
Position & No & No & Yes & Yes \\
Ex. short duration & No & No & No & Yes \\
Observations & 4523 & 4523 & 4523 & 4170 \\
R2 & 0.0954 & 0.0971 & 0.0979 & 0.103 \\
Not All & &
\end{tabular}

Notes: All regressions use robust standard errors clustered at the subject level. Only subjects who completed all 10 iterations are included ${ }^{*} p<0.1,{ }^{* *} p<0.05,{ }^{* * *} p<0.01$. In all specifications, monetary values are expressed in units of $\$ 10,000$ to make the table more readable.

Diff Income ${ }^{+1}$ is the difference in income between Societies B and A for the individual in the position directly above the subject's own. Diff Income $e^{+2}$ is similarly defined for the individual two positions above the subject. Diff Income ${ }^{7}$ is the difference in income between Societies B and A for the richest (i.e., position 7) individual. Diff Income ${ }^{1}$ is similarly defined for the poorest individual. 
Table A14: Heterogeneity in Inequality Aversion in the Own-Income Varies Sample

Dep. var: Chose Second Distribution

(1) (2) (3)

(4)

Democrat Republican Not Fair Distribution Fair Distribution

\begin{tabular}{lcccc}
\hline Diff Income $^{+1}$ in B vs. A & $-0.0159^{* *}$ & -0.0200 & $-0.0118^{* *}$ & -0.0126 \\
& {$[0.00772]$} & {$[0.0131]$} & {$[0.00574]$} & {$[0.00818]$} \\
Diff Income $^{+2}$ in B vs. A & 0.000861 & $-0.0240^{* *}$ & 0.00315 & -0.00712 \\
& {$[0.00800]$} & {$[0.0107]$} & {$[0.00527]$} & {$[0.00894]$} \\
Diff Income $^{1}$ in B vs. A & $0.160^{* * *}$ & $0.107^{* * *}$ & $0.159^{* * *}$ & $0.0767^{* * *}$ \\
& {$[0.0212]$} & {$[0.0309]$} & {$[0.0151]$} & {$[0.0205]$} \\
Diff Income $^{O W N}$ in B vs. A & $0.213^{* * *}$ & $0.249^{* * *}$ & $0.191^{* * *}$ & $0.261^{* * *}$ \\
& {$[0.0103]$} & {$[0.0175]$} & {$[0.00793]$} & {$[0.0107]$} \\
Diff Income $^{7}$ in B vs. A & $-0.0386^{* * *}$ & -0.0115 & $-0.0467^{* * *}$ & $-0.0241^{* * *}$ \\
& {$[0.00655]$} & {$[0.0102]$} & {$[0.00469]$} & {$[0.00752]$} \\
\hline Above Two/One Diff. & .01673 & -.00393 & $.01493^{*}$ & .00549 \\
Question-Order FE & No & No & No & No \\
Position & No & No & No & No \\
Ex. short duration & No & No & No & No \\
Observations & 1560 & 655 & 3302 & 1243 \\
\hline Not Al & & &
\end{tabular}

Notes: All regressions use robust standard errors clustered at the subject level. The sample in this table includes participants in the "Own Income" experiment (see text for details). Only subjects who completed all 10 iterations are included ${ }^{*} p<0.1,{ }^{* *} p<0.05,{ }^{* * *} p<0.01$. In all specifications, monetary values are expressed in units of $\$ 10,000$ to make the table more readable. In columns (1) and (2) regressions are run separately on the subsamples of, respectively, self-identified Democrats and Republicans. In columns (3) and (4) we divide the sample based on responses to the question, "Do you feel that the distribution of income and wealth in the US today is fair or should be more evenly distributed among a larger portion of the population?" DiffIncome ${ }^{+1}$ is the difference in income between Societies B and A for the individual in the position directly above the subject's own. DiffIncome ${ }^{+2}$ is similarly defined for the individual two positions above the subject. Diff Income ${ }^{1}$ is the difference in income between Societies B and A for the poorest (i.e., position 1) individual. Diff Income ${ }^{7}$ is similarly defined for the richest individual. 
Table A15: Heterogeneity in Inequality Aversion

\begin{tabular}{|c|c|c|c|c|c|c|c|c|}
\hline & \multicolumn{8}{|c|}{ Dep. var: Chose Second Distribution } \\
\hline & $\begin{array}{c}(1) \\
\text { Income } \leq 49 \mathrm{k}\end{array}$ & $\begin{array}{c}(2) \\
\text { Income } \geq 49 \mathrm{k}\end{array}$ & $\begin{array}{c}(3) \\
\text { Age } \leq 30\end{array}$ & $\begin{array}{c}(4) \\
\text { Age } \geq 30\end{array}$ & $\begin{array}{c}(5) \\
\text { Male }\end{array}$ & $\begin{array}{c}(6) \\
\text { Female }\end{array}$ & $\begin{array}{c}(7) \\
\text { No College }\end{array}$ & $\begin{array}{c}(8) \\
\text { College }\end{array}$ \\
\hline Diff Income In $^{+1}$ in vs. A & $\begin{array}{c}-0.0288^{* * *} \\
{[0.00588]}\end{array}$ & $\begin{array}{c}-0.0437^{* * *} \\
{[0.00589]}\end{array}$ & $\begin{array}{c}-0.0328^{* * *} \\
{[0.00518]}\end{array}$ & $\begin{array}{c}-0.0426^{* * *} \\
{[0.00695]}\end{array}$ & $\begin{array}{c}-0.0348^{* * *} \\
{[0.00581]}\end{array}$ & $\begin{array}{c}-0.0378^{* * *} \\
{[0.00593]}\end{array}$ & $\begin{array}{c}-0.0346^{* * *} \\
{[0.00648]}\end{array}$ & $\begin{array}{r}-0.0374^{* * *} \\
{[0.00543]}\end{array}$ \\
\hline Diff Income In $^{+2}$ in vs. A & $\begin{array}{c}0.00419 \\
{[0.00498]}\end{array}$ & $\begin{array}{l}-0.00514 \\
{[0.00536]}\end{array}$ & $\begin{array}{c}0.00218 \\
{[0.00459]}\end{array}$ & $\begin{array}{l}-0.00584 \\
{[0.00608]}\end{array}$ & $\begin{array}{l}-0.00264 \\
{[0.00499]}\end{array}$ & $\begin{array}{c}0.00168 \\
{[0.00537]}\end{array}$ & $\begin{array}{l}0.000395 \\
{[0.00562]}\end{array}$ & $\begin{array}{l}-0.00126 \\
{[0.00482]}\end{array}$ \\
\hline Diff Income ${ }^{1}$ in B vs. A & $\begin{array}{l}0.205^{* * *} \\
{[0.00949]}\end{array}$ & $\begin{array}{l}0.185^{* * *} \\
{[0.00933]}\end{array}$ & $\begin{array}{l}0.194^{* * *} \\
{[0.00794]}\end{array}$ & $\begin{array}{l}0.198^{* * *} \\
{[0.0122]}\end{array}$ & $\begin{array}{c}0.198^{* * *} \\
{[0.00878]}\end{array}$ & $\begin{array}{l}0.191^{* * *} \\
{[0.0102]}\end{array}$ & $\begin{array}{l}0.201^{* * *} \\
{[0.0102]}\end{array}$ & $\begin{array}{l}0.191^{* * *} \\
{[0.00881]}\end{array}$ \\
\hline Diff Income ${ }^{7}$ in B vs. A & $\begin{array}{c}-0.0394^{* * *} \\
{[0.00572]}\end{array}$ & $\begin{array}{c}-0.0457^{* * *} \\
{[0.00579]}\end{array}$ & $\begin{array}{c}-0.0491^{* * *} \\
{[0.00501]}\end{array}$ & $\begin{array}{c}-0.0313^{* * *} \\
{[0.00694]}\end{array}$ & $\begin{array}{c}-0.0323^{* * *} \\
{[0.00566]}\end{array}$ & $\begin{array}{c}-0.0532^{* * *} \\
{[0.00585]}\end{array}$ & $\begin{array}{c}-0.0327^{* * *} \\
{[0.00623]}\end{array}$ & $\begin{array}{r}-0.0498^{* * *} \\
{[0.00538]}\end{array}$ \\
\hline Above Two/One Diff. & $.03298 * * *$ & $.03854^{* * *}$ & $.03498 * * *$ & $.03679 * * *$ & $.03217 * * *$ & $.03944 * * *$ & $.03495^{* * *}$ & $.03613^{* * *}$ \\
\hline Question-Order FE & No & No & No & No & No & No & No & No \\
\hline Position & No & No & No & No & No & No & No & No \\
\hline Ex. short duration & No & No & No & No & No & No & No & No \\
\hline Observations & 7226 & 7182 & 9737 & 4671 & 7892 & 6516 & 6056 & 8352 \\
\hline
\end{tabular}

Notes: All regressions use robust standard errors clustered at the subject level. The sample in this table includes participants in the

"Absolute Differences" and "Percentage Differences" experiments run in September 2013 (see text for details). Only subjects who completed all 10 iterations are included ${ }^{*} p<0.1,{ }^{* *} p<0.05,{ }^{* * *} p<0.01$. In all specifications, monetary values are expressed in units of $\$ 10,000$ to make the table more readable. Diff Income $e^{+1}$ is the difference in income between Societies B and A for the individual in the position directly above the subject's own. Dif Income $^{+2}$ is similarly defined for the individual two positions above the subject. Dif I Income $e^{1}$ is the difference in income between Societies B and A for the poorest (i.e., position 1) individual. Diff Income ${ }^{7}$ is similarly defined for the richest individual. 